\title{
TESTING HYPOTHESES OF NEURAL EVOLUTION IN GYMNOTIFORM ELECTRIC FISHES USING PHYLOGENETIC CHARACTER DATA
}

\author{
James S. Albert, ${ }^{1}$ Michael J. Lannoo, ${ }^{2}$ And Tamaki Yuri ${ }^{3}$ \\ ${ }^{1}$ Nippon Medical School, Department of Anatomy, Sendagi 1-1-5, Bunkyo-ku, Tokyo 113, Japan \\ E-mail: albert@nms.ac.jp \\ ${ }^{2}$ Muncie Center for Medical Education, Indiana University School of Medicine, Ball State University, Muncie, Indiana 47306 \\ E-mail: mlannoo@gw.bsu.edu \\ ${ }^{3}$ Museum of Zoology, University of Michigan, Ann Arbor, Michigan 48109-1079 \\ E-mail: komadori@umich.edu
}

\begin{abstract}
In this paper, we propose a method to test alternative hypotheses of phenotypic evolution. The method compares patterns observed in phylogenetic character data with patterns expected by explicit models of evolutionary process. Observed patterns of character-state diversity are assessed from four properties of character-state change derived from a phylogenetic analysis: the sequence and correlation of transformations on a cladogram and the spatial and functional localization of these transformations to parts of an organism. Patterns expressed in terms of the localization of transformations are compared with the expectations of null models that the number of transformations is proportional to measures of size or complexity. Deviations from the values expected by the null models are then compared with qualitative expectations of the models.

The method is applied to characters in the nervous system of gymnotiform electric fishes. Patterns in the diversity of 63 reconstructed character-state changes are compared with the expectations of 10 published models of neural evolution. A total of 63 expectations are reviewed, of which $33(52 \%)$ are found to be consistent with the gymnotiform neural data. In general, the models reviewed are not successful at making global predictions, in part because they have been cast in excessively general terms. The data support the conclusion that evolution in the nervous system of gymnotiforms has involved a mosaic of processes, each operating differentially on functional and developmental systems and at different spatial and temporal scales. The results also indicate that more refined models are required, each making more explicit predictions.
\end{abstract}

Key words.-Anatomy, brain, developmental constraints, electric organs, histology, morphology, phylogenetic analysis, sensory receptors, specialization, vertebrate.

Received June 20, 1997. Accepted July 14, 1998.

Phenotypic evolution may be viewed as a change in the developmental program that descendants inherit from their ancestors (Garstang 1922; Fink 1982). From the phylogenetic perspective, embryologists may be said to investigate the rules by which an ontogeny constructs a phenotype and comparative biologists the rules by which such ontogenies are modified (Hamburger 1952; Noden 1991; Northcutt 1992). Once identified, these rules contribute to explaining observed patterns of morphological diversification (Bateson 1894; Alberch et al. 1979; Alberch 1980; Cheverud et al 1985). Much attention has been directed to elucidating the rules underlying change in vertebrate nervous systems, and numerous specific models have been proposed (e.g., Ebbesson 1984; Endler 1992; Roth et al. 1992; Kaas 1993).

As historical events, phylogenetic changes are unique, and the sequence of evolutionary modifications resulting in an observed phenotype may not be replicated. Evolutionary biology is therefore fundamentally a historical rather than a hypothetico-deductive science (Sober 1988). It is nevertheless possible to test the consistency of observed patterns of diversification with the expectations of alternative models of evolutionary process, and several methods have been developed (Cartmill 1981; Emerson 1984, 1988; Lauder and Liem 1989; Hayes and Garland 1995; Schaefer and Lauder 1996). The utility of these approaches depends on the extent to which the models examined predict explicit patterns of phylogenetic and/or phenotypic diversity. Expectations of phylogenetic pattern may pertain to any aspect of organic diversity, and are commonly expressed in terms of the temporal distribution of character-state transformations or steps on a cladogram (e.g., Ridley 1983; Maddison 1990; Huelsenbeck and Rannala 1997).

Phylogenetic patterns may also be observed in the physical localization of morphological transformations to regions of an organism. The relative number of character-state changes observed in comparable anatomical regions provides an estimate of the relative rates of morphogenetic evolution of these regions. Character localization (CL) is the relative number of phylogenetic changes observed among comparable morphological categories. CL may be used to quantify regional heterogeneities in the accumulation of character-state changes, and thereby be used to identify loci of evolutionary activity. CL is based on phylogenetic (cladistic) methods for identifying character-state transformations and possesses the numerical tractability of methods that examine patterns of phenotypic diversity from character-state data (Lauder and Liem 1989; Harvey and Pagel 1991; Hayes and Garland 1995; Omland 1997). CL differs from other methods by focusing on the position of individual phylogenetic characters within embryologically or functionally defined categories.

Here we introduce a general procedure to compare patterns expected by explicit models of phenotypic transformation with observed patterns of character-state diversity. This method extends the logic of Lauder and Liem (1989) by comparing the statistical properties of phylogenetic characters, rather than features of terminal taxa (Ridley 1983; Maddison 1990). Parametric statistical methods for describing variation and generating expected values have proven diffi- 
cult to apply to interspecific comparisons because the nested hierarchy of relationships among taxa violates the assumption of sampling independence (Felsenstein 1985; Harvey and Pagel 1991; Garland et al. 1992). However, statistical methods may be applied to character-state data when the characters are phylogenetically independent.

In this paper we apply the statistical procedure to characterstate data derived from a phylogenetic study of the nervous system of gymnotiform electric fishes (Albert 1999). Gymnotiform fishes are well suited to studies of neural diversification. The nervous system of these fishes is highly specialized for electroreception and has been extensively explored as a model in neuroethology (see Heiligenberg 1991; Rose and Canfield 1993). Individual gymnotiform fishes continually emit weak electric discharges that they use in object location and communication (Hopkins 1972; Hopkins et al. 1990). The electrosensory system of gymnotiform fishes is organized into parallel information processing channels, each tuned to different properties of the electrosensory environment (Carr and Maler 1986; Shumway 1989a; Maler and Mugnaini 1994). Details of ultrastructure, function, and development are now sufficiently understood in several gymnotiform species (Lannoo et al. 1990, 1991; Vischer et al. 1990; Kirschbaum 1994; Rasnow 1994; Zakon et al. 1995; Zupanc and Horschke 1995; Wong 1997) to test the patterns predicted by competing models of evolutionary process.

Gymnotiform fishes are also attractive because the phylogenetic context now exists in which to trace the history of transformations in the neural circuitry underlying complex behavioral repertoires (Finger et al. 1986; Heiligenberg et al. 1996). The more than 100 species of gymnotiform fishes have been the subject of several systematic studies using both morphological and molecular data (Triques 1993; Mago-Leccia 1994; Alves-Gomes et al. 1995; Albert and Campos-daPaz 1998; Albert 1999), and position of gymnotiforms among teleost fishes is also now well understood (Fink and Fink 1981, 1996).

The specific goals of this paper are: (1) to outline four methods of assessing phylogenetic patterns in character-state data; (2) to develop a quantatative method for generating expectations in the number of character-state changes among brain divisions adjusted for measures of size and complexity; and (3) to use comparisons between observed and expected numbers of character-state changes to evaluate 10 published models of neural evolution.

\section{Materials ANd Methods}

\section{A Test of Hypotheses of Evolution}

The method to test hypotheses of evolution is presented in four steps, following the logic of Lauder and Liem (1989).

Step 1: Phylogenetic Analysis.-Undertake a phylogenetic analysis to recover interrelationships among the relevant taxa, and isolate individual homologous characters. It is widely agreed that identifying homologous characters in the context of a hypothesis of phylogenetic relationships is the basis for macroevolutionary investigation (Hennig 1966; Patterson 1982). Features of interest (e.g., "key innovations") may be identified from the study of physiology and behavior, yet characters must be examined in a phylogenetic context to be recognized as homologous (Patterson 1982; Prum 1990).

Binary characters and unordered multistate characters derived from a phylogenetic (cladistic) analysis are independent and therefore amenable to statistical treatment. This condition is not satisfied by characters-states nested on a tree (e.g., ordered multistate characters, additive binary characters). Phylogenetic analysis of raw morphological data requires that quantitative differences be transformed into qualitative character states.

Step 2: Models.-Generate mechanistic models of phenotypic change, and outline some of their expected phylogenetic consequences. The models may posit any combination of natural agents governing the rate or direction of phenotypic changes. To be useful, however, the models should be explicit enough to be falsifiable by at least some patterns of character data. The proposed agents may exert their influence at any level of the organizational hierarchy (i.e., physicochemical, genetic, epigenetic, behavioral, social), and their expectations may pertain to phenotypes at any of these levels.

The models may seek to explain any aspect of the order, complexity, or specialization observed in animal nervous systems, and the predictions may be addressed to character transformations involving function, tissue type, spatial scale, or position in developmental or phylogenetic hierarchies (Maynard Smith et al. 1985). The null hypotheses against which deviations can be assessed assume that characters are distributed randomly with respect to these parameters.

Step 3: Assessing Phenotypic Diversity.-Document empirical patterns in character-state data. Four methods of assessing patterns in character-state data are used here: the (1) phylogenetic sequence; (2) correlation; (3) spatial localization; and (4) functional localization of character-state changes. Once identified, patterns of character-state diversity may be compared with patterns expected by alternative models of evolution.

Step 4: General Conditions.-Circumscribe general conditions under which models apply. Three parameters that may limit the generality of models are examined: size (or spatial scale), tissues or organ system, and taxon. The limitations of several models are examined in the Discussion.

\section{Comparative Neurology}

Abbreviated descriptions of 55 neural characters and states are provided in Table 1. Complete descriptions of these characters are provided in Albert (1999). Distributions of character states among 33 gymnotiform species and two outgroup terminal taxa are listed in Table 2. Specimens were obtained from museum collections, commercial aquarium dealers, and field collections. Observations were taken from the morphology of nervous tissues from 33 gymnotiform species, including representatives from each of the five recognized families and all 27 recognized genera (Fig. 1). Serial sections of the brain were prepared from specimens in 25 gymnotiform species (Albert 1999). Whole mounts of the integument from the left side of the head were prepared for 16 gymnotiform species and stained with methylene green to visualize electroreceptor organs. 
TABLE 1. Abbreviated descriptions of characters and states. Numbers in parentheses are steps on the most-parsimonious tree. Complete character descriptions in Albert (1999). Abbreviations: Dc, telencephalic nucleus dorsalis centralis; Dca, telencephalic dorsalis centralis anterior; Dm, telencephalic dorsalis medialis; Dp, telencephalic dorsalis posterior; EOD, electric organ discharge; EG, eminentia granularis; ELL, electrosensory lateral line lobe; NE, nucleus electrosensorius; NV, Trigeminal nerve root; NVIIr, recurrent ramus of facial nerve; PO, postorbital distance of neurocranium; SPPn, sublemniscal prepacemaker nucleus; TO, tectum opticum; TS, torus semicircularis.

1. Nasal capsule. 0 : closer to orbit. 1: closer to tip of snout. (3)

2. Anterior nares. 0: out of gape. 1: inside gape. (2)

3. Anterior narial pore. 0: tubular. 1: sessile. (1)

4. Olfactory bulb position. 0 : sessile. 1: pedunculate. (1)

5. Olfactory bulb size. 0 : large. 1 : small. (1)

6. Dorsal telencephalic nucleus. 0: Dm large, Dca small. 1: Dm small, Dca large. (1)

7. Posterior pole of Dp. 0: relatively small. 1: relatively large. (1)

8. Telencephalic area dorsalis centralis. 0: no lateral area. 1: lateral area present. (1)

9. Lateral Dc cells. 0: no large cells. 1: with large cells. (1)

10. Prepacemaker nucleus. 0: absent. 1: present. 2. (1)

11. Nucleus electrosensorius (NE). 0: absent. 1: present. 2. (2)

12. Lateral preglomerular nucleus (PG1). 0: absent. 1: present. 2. (2)

13. EOD frequency shift/SPPn. 0: absent. 1: bimodal. 2: unimodal. (3)

14. Jamming avoidance response. 0: absent. 1: present. (2)

15. Habitat utilization. 0: small streams. 1: large river channels. (10)

16. Neurohypophysis. 0 : sessile. 1: on stalked hypothalamus. (1)

17. Lens. 0: contacting integumental surface. 1: subdermal. (2)

18. Retina. 0: more than 0.50 PO. 1: less than 0.20 PO. (2)

19. Posterior optic tectum. 0: large; extends to NV. 1: small; remote from NV. (1)

20. Torus semicircularis. 0: thin, undivided. 1: segmented. 2: 1213 layers. (2)

21. Preaeminential nucleus. 0: absent. 1: two. 2: four. (2)

22. Trochlear and oculomotor systems. 0 : robust. 1: minute or absent. (1)

23. Accessory optic system. 0: present. 1: absent. (2)

24. Integumental taste buds. 0: present. 1: absent. (1)

25. Schreckstoff/club cells. 0: present. 1: absent. (1)

26. Ampullary organ rosettes. 0: absent. 1: present. (1)

27. Tuberous electroreceptors. 0: absent. 1: present. (1)

28. Supraorbital lateral line canal. 0: separate from infraorbital. 1: nasal loop. (1)

29. Rostral infraorbital neuromast. 0: remote from rostral pore. 1: near rostral pore. (3)

30. Preopercular/mandibular line. 0: no specialization. 1: neural mental organ. (1)

31. Preotic lateral line ganglia. 0: separate. 1: fused. (1)

32. Supratemporal lateral line. 0 : short and straight. 1: long with posterior limb. (1)

33. Posterior lateral line nerve. 0: joined with NVIIr. 1: separate from NVIIr. (1)

34. Posterior lateral line pores. 0: shallow. 1: tubular. (1)

35. Corpus cerebellum. 0: small. 1: large. (1)

36. Anterior corpus cerebellum. 0: large, to middle of TO. 1: small, posterior to midlength. (2)

37. Lateral valvula cerebellum. $0:<$ medial valvula. 1 : subequal with medial valvula. (3)

38. Locomotion foraging. 0: forward lunge. 1: scanning. (3)

39. Lateral line afferents. 0: intermingled. 1: fasciculated. (1)

40. Posterior EG. 0: thick. 1: thin. (1)

41. Depth of posterior EG. 0: thick. 1: thin. (1)

42. Anterior extent of EG. 0: to tectum. 1: posterior to tectum. (1)

43. Posterior extent of EG. 0: to vertical with ELL. 1: posterior to vertical with ELL. (2)

44. ELL segments. 0: absent. 1: two. 2: four. (2)

45. Ventral margin of ELL. 0: curved. 1: flat. (2)
TABLE 1. Continued.

46. Spherical cells. 0: without basilar dendrite. 1: with basilar dendrite. (1)

47. Medullary pacemaker nucleus. 0: absent. 1: present. (1)

48. Pacemaker cells. 0: small, not contacting ventral margin. 1 : large, contacting margin. (2)

49. Maximum EOD frequencies. 0: less than c. $700 \mathrm{~Hz}$. 1: more than c. $1200 \mathrm{~Hz}$. (1)

50. EOD form. 0: pulse, low repetition rate. 1: wave, high repetition rate. (1)

51. EOD phases. 0: monophasic. 1: multiphasic. (4)

52. EOD duration. $0: \mathrm{c} .1 \mathrm{~ms} .1$ : more than $2 \mathrm{~ms}$. (2)

53. EOD prepulse. 0: absent. 1: present. (2)

54. Axial electric organ. 0: myogenic in adults. 1 : neurogenic in adults. (1)

55. Electromotoneurons. 0: parallel with neuraxis. 1: recurved. (2)

All living animals used in this study were anesthetized with 3-aminobenzoic acid ethyl ester (MS 222, Sigma, St. Louis, MO), perfused intracardially or immersion-fixed with $10 \%$ formalin and stored in the same solution. Histological methods follow Ito et al. $(1986,1997)$. Additional slides of teleost brains were examined from personal collections and those of $\mathrm{H}$. Ito (referenced in Ito 1978). Drawings of gross brain morphology (e.g., Fig. 2) and representative transverse sections were compiled into an atlas for each species following Maler et al. (1990). Following Tuge et al. (1968), 12 transverse sections were selected for detailed assignments of labels (see Albert 1999). The use and limits of alcohol-preserved specimens in comparative studies of fish brain morphology are discussed by Eastman and Lannoo (1995). The original research reported herein was performed under guidelines established by the University of Michigan and Ball State University.

The neural organization of Apteronotus leptorhynchus was examined in detail to confirm extensive literature reports on this species (e.g., Maler et al. 1990). The brains of four specimens were prepared using conventional cell body and tract staining methods, and one specimen each was subjected to a modified version of the Bodian and Golgi silver impregnation methods (Ito et al. 1986). Electroreceptors, lateral line nerves, and nerve ganglia were visualized from seven specimens by clearing with trypsin and staining with Sudan Black B (Nishikawa 1987).

Volumetric analyses were conducted following Northcutt and Braford (1980) and Albert et al. (1999). Volumes of whole brains and brain divisions were measured in specimens representing 17 gymnotiform species (Fig. 3) by immersing fixed brains in fixative and dissecting the following brain divisions for weighing: olfactory bulbs (BO), telencephalon (TE), diencephalon (DI, including thalamus and inferior lobes), midbrain tectum (MT, optic tectum and torus semicircularis), midbrain tegmentum (TG, to commissure ansularis), cerebellum (CE, corpus and valvula), and medulla oblongata (MO, including electrosensory, facial and vagal lobes). Optic nerves were trimmed $1 \mathrm{~mm}$ from the chiasm, cranial nerves were transected where they emerge from the brain, and neither they nor the meninges, blood vessels, or choroid plexus were included in the weights. Each brain division was blotted immediately before weighing. All measurements were made on an analytical balance and the ac- 
TABLE 2. Matrix summarizing comparative data on the neuromorphology of gymnotiforms. Characters grouped by tens; abbreviated descriptions of the 55 characters in Table 1. Criteria for selecting and coding the 35 terminal taxa examined are provided by Albert (1999). ?, no data or not applicable; $P$, polymorphic ( 0 and 1). Dubious taxonomic names are in quotations. Lateral preglomerular nucleus (Striedter 1992). EOD frequency shift (Heiligenberg et al. 1996). Lateral valvula cerebellum (cross-sectional area at isthmus). Locomotion/ foraging (Lannoo and Lannoo 1993). Lateral line afferents (Lannoo and Maler 1990). EOD phases (Sullivan 1993). EOD duration (AlvesGomes et al. 1995). EOD prepulse (Alves-Gomes et al. 1995). Characiformes: Accessory optic system (pers. obs.); depth of posterior EG, anterior extent of EG, posterior extent of EG, ventral margin of ELL, spherical cells, EOD form, phases, duration, and prepulse (not applicable). Siluriformes: Spherical cells (homology of round cells not assessed). EOD form, phases, duration, and prepulse (not applicable). Rhamphichthys rostratus: habitat utilization ( $R$. apurensis, lower Orinoco). Gymnorhamphichthys hypostomus: habitat utilization (G. hypostomus, upper Orinoco). Gymnorhamphichthys hypostomus: lateral line afferents (pers. obs.). Gymnorhamphichthys rondoni: preopercular/mandibular line (myogenic mental organ). Steatogenys elegans: Dcl cells (cells more densely packed). Steatogenys elegans: preopercular/mandibular line (myogenic mental organ), locomotion/foraging $(S$. duidae $=1)$. Pacemaker cells (large and small cells partitioned). Brachyhypopomus pinnicaudatus: EOD phases (Sullivan, pers. comm.). Porotergus n. sp. C (Albert 1999): preopercular/ mandibular line (mental organ of unknown structure). Sternarchogiton n. sp. B (Albert 1999).

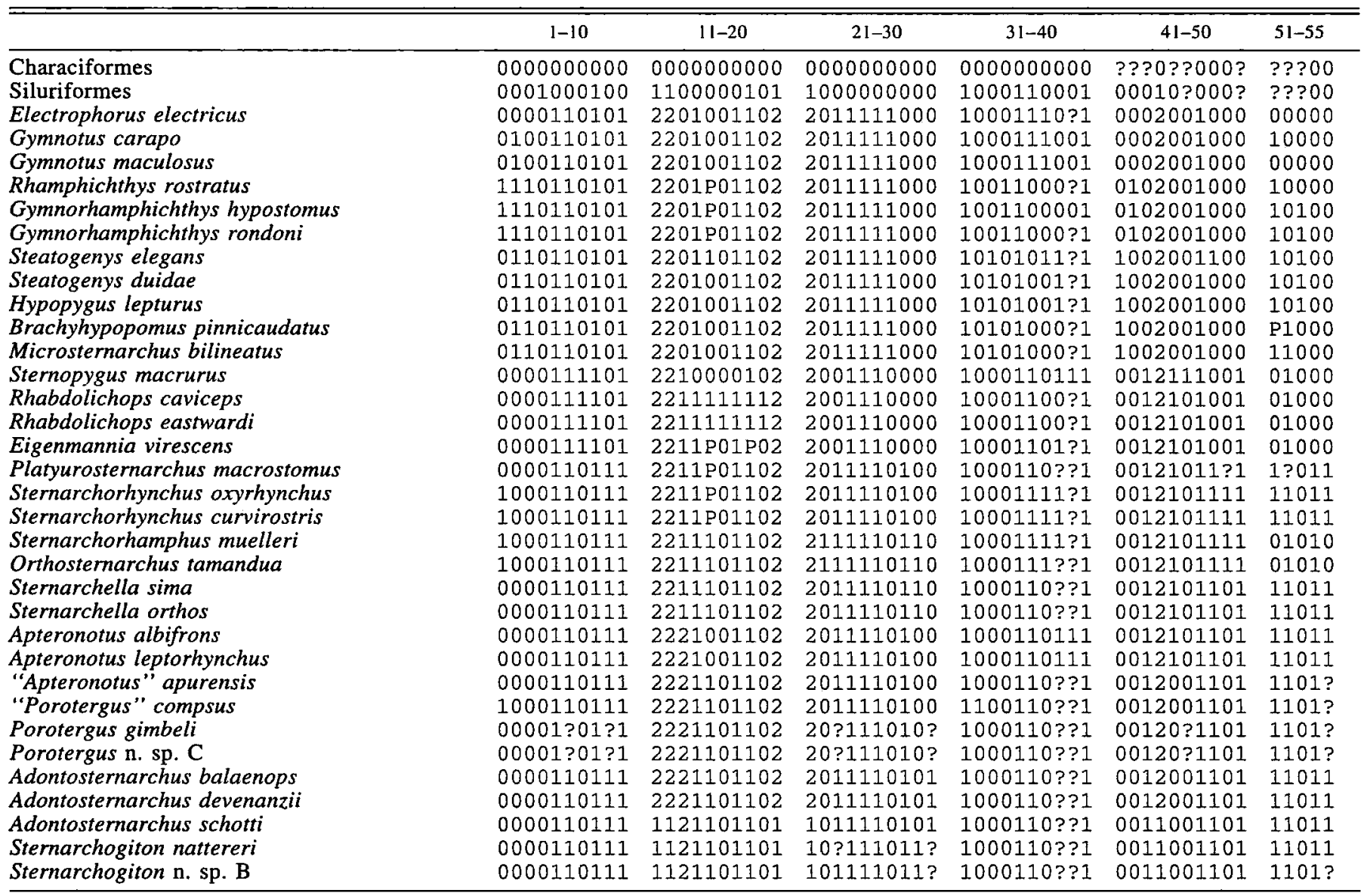

curacy of 10 repeated measurements estimated on a small brain division (c. $20 \mathrm{mg}$ ) was $\pm 0.5 \%$.

The relative number of parts within each brain division, assessed against the total number of parts of the brain, was used to estimate the relative complexity of brain divisions. The parts employed are the nuclei (named cell groups) and forebrain subdivisions of Maler et al. (1990) as amended by Albert (1999). This measure of complexity is the nonhierarchical object complexity of McShae (1996).

\section{Tree Topology}

Character evolution was traced on a hypothesis of gymnotiform interrelationships generated from previous studies (Albert and Campos-da-Paz 1998; Albert 1999). The tree topology depicted in Figures 1 and 3 is identical with that of Albert (1999) and Albert and Campos-da-Paz (1998) and differs from the preferred topology of Alves-Gomes et al. (1995) with respect to the position of Sternopygus. Figure 1 includes only taxa for which neural data were coded. Figure 3 includes only the 17 gymnotiform and two outgroup species for which volumetric data of brain divisions were measured. Exclusion of the neural characters (Table 1) from the larger data matrix used to generate the hypothesis of interrelationships does not alter the tree topology. Analysis of the neural data alone yields a similar tree topology, with the notable difference of placing Gymnotidae as the sister-taxon to the clade Rhamphichthyidae + Hypopomidae.

Detailed descriptions of the phylogenetic methods and characters and a discussion of alternative tree topologies are provided by Albert (1999). In brief, 250 morphological char- 


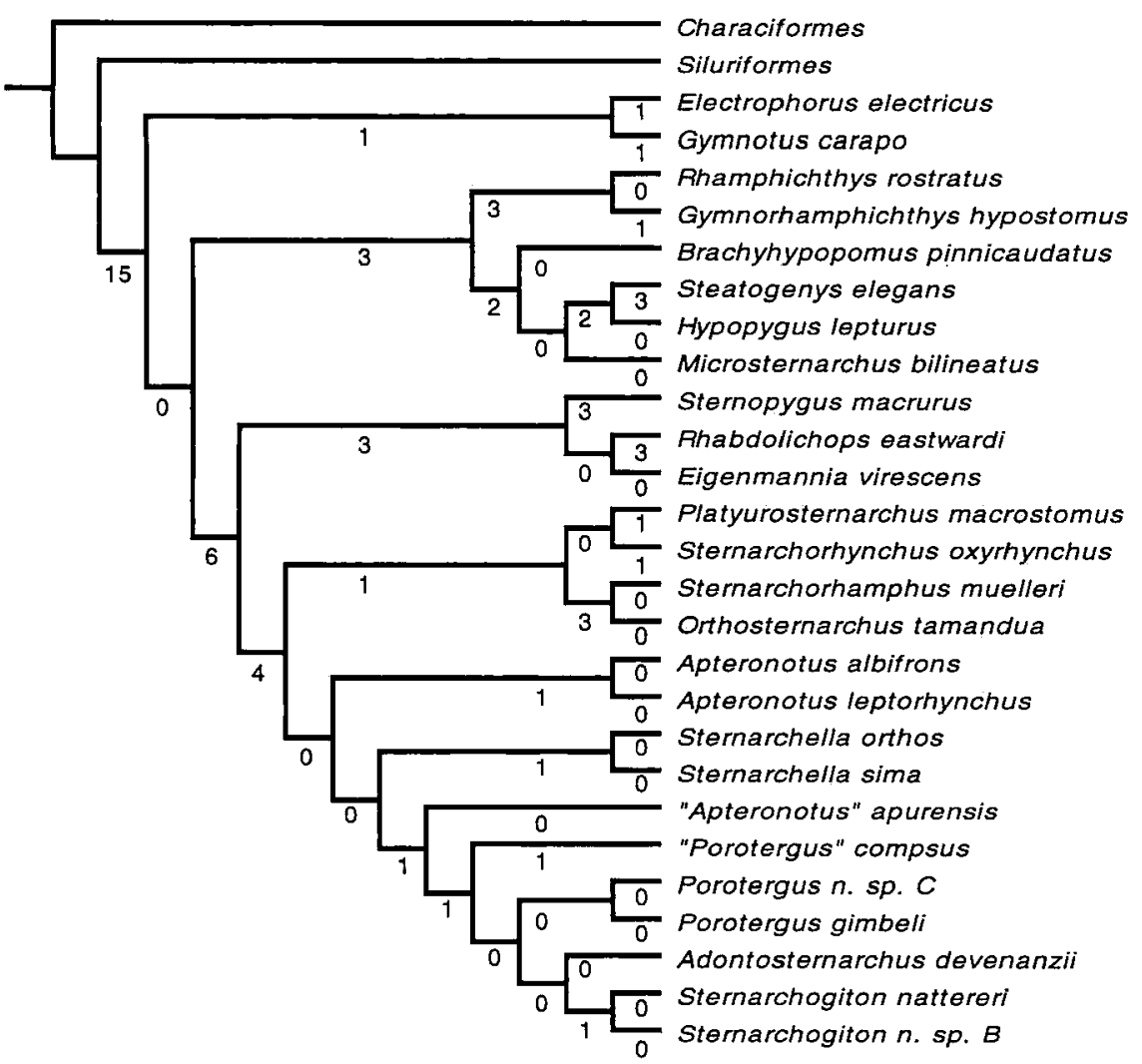

FIG. 1. Phylogenetic interrelationships among 33 gymnotiform species for which neural character data were coded. Taxonomy and tree topology from Albert (1999). Numbers of neural character-state transformations indicated at each node. There are 63 steps distributed among 25 of the $52(48 \%)$ ingroup nodes and terminals.

acters were coded for 39 gymnotiform and two outgroup taxa (Albert and Campos-da-Paz 1998) and analyzed with maximum parsimony using a test version of PAUP 4.0 , written by David L. Swofford (see Swofford 1993). The resulting tree topology of that analysis is a strict consensus of three equally parsimonious fundamental cladograms, each consisting of 579 steps, with an ensemble consistency index of 0.50 and a rescaled consistency index of 0.41 (fig. 1 of Albert and Campos-da-Paz 1998). For that study, branch support or decay indices (Bremer 1988) were determined with the aid of TreeRot (Sorenson 1996).

Phylogenetic characters were coded from examination of more than 3500 specimens representing about 90 gymnotiform species and all 27 recognized genera (Albert and Campos-da-Paz 1998; Albert 1999). Personal collections provided 80 lots with 393 specimens, all of which are deposited in the zoological collections of the Universidad Central de Venezuela and the University of Michigan. For osteological examination more than 400 specimens representing about 70 gymnotiform species were cleared and stained for bone and cartilage using a modified version of the enzyme technique of Taylor and Van Dyke (1985). Character states were examined in multiple outgroups, including Siluriformes, Characiformes (Fink and Fink 1981, 1996; Albert 1999), and other teleost groups (Tuge et al. 1968; Ito 1978).

\section{Models Reviewed}

The expectations of 10 published models of neural evolution were examined (Table 3 ). The models were selected to represent a broad range of perspectives, including representatives of several different schools (Butler and Hodos 1996; Nieuwenhuys et al. 1998). To facilitate comparison, the models are classified into two general categories: models of specialization and models of constraint.

Models of specialization posit the action of natural selection on variation in the sensitivity of neuronal populations to environmental heterogeneity. These models refiect a widely held view of neural evolution that selection for sensory and/or behavioral specializations results in adaptation to local environments or habitats (Fisher 1958; Mayr 1960; AriensKappers et al. 1960; West-Eberhard 1989; Endler 1992).

Models of habitat specialization (model 1) expect character evolution to be initiated in the sensory-motor periphery, more steps in the periphery, cells (and cell groups) in direct contact with the peripheries to exhibit more intraspecific variation than cells in other portions of the central nervous system (Finlay et al. 1987), and speciation to be accompanied by behavioral and neuromorphological changes (Webster 1984).

The model of neurobiotaxis (model 2) expects neuronal cell bodies (soma) to change position toward their sources of physiological stimulation in phylogeny; for example, sensory neurons become located more peripherally and motor neurons more centrally (Ariens-Kappers et al. 1960). Sensory-motor neurons are expected to exhibit greater developmental variation and more phylogenetic diversity. As advanced by Schnitzlein (1977) and Wilczynski (1984), this model expects forebrain olfactory, midbrain optic, and hind- 


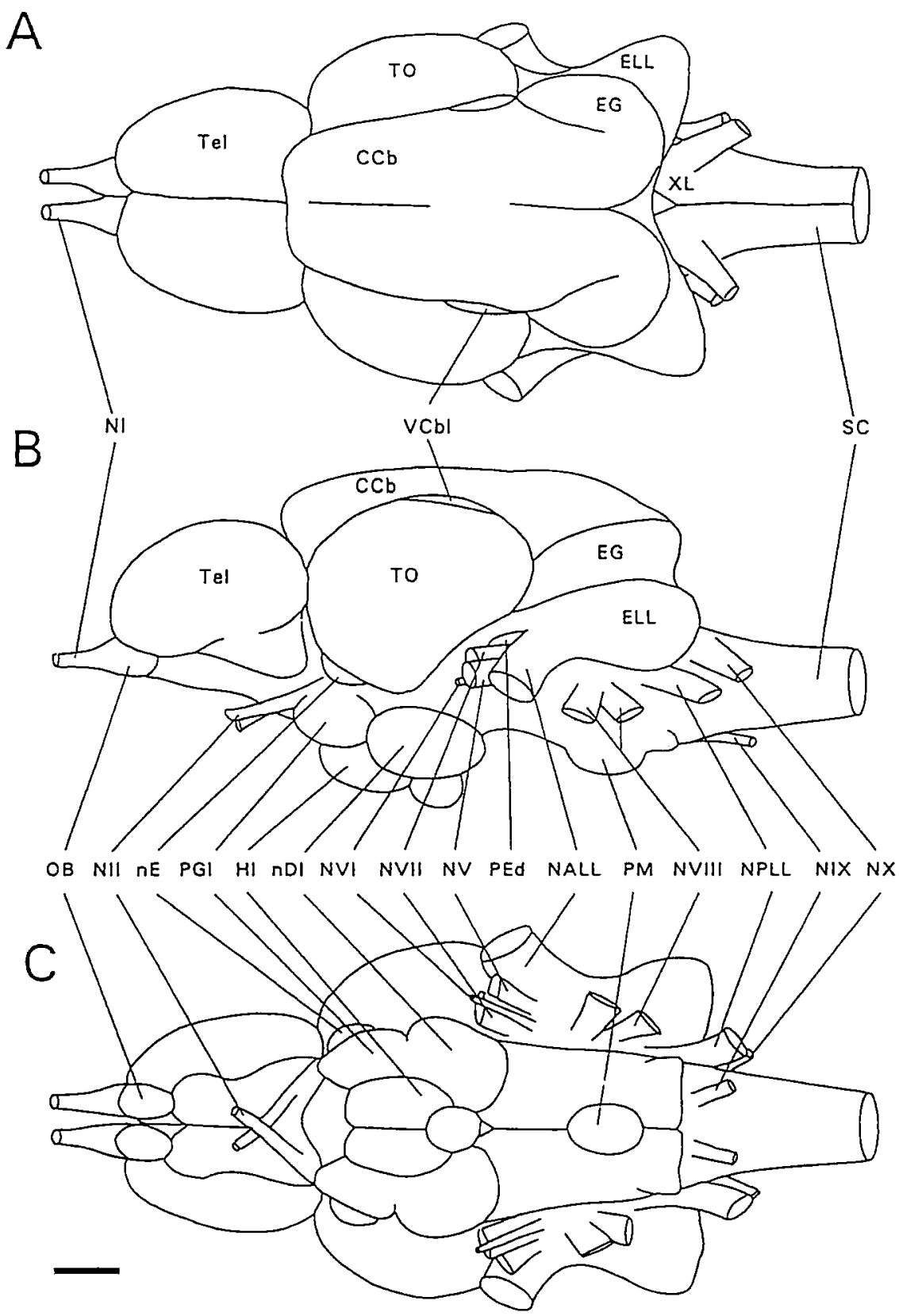

Fig. 2. Dorsal (A), lateral (B), and ventral (C) views of the brain of Apteronotus leptorhynchus (Apteronotidae). Anterior to left, dorsal to top of page. Abbreviations: $\mathrm{CCb}$, corpus cerebellum; EG, eminentia granularis; ELL, electrosensory lateral line lobe; Hl, lateral nucleus of hypothalamus; NI, olfactory nerve; NII, optic tract; NV, trigeminal and profundus nerves; NVI, abducens nerve; NVIII, eighth nerve; NIX, hypoglossal nerve; NX, vagal nerve; NALL, anterior lateral line nerves; nDI, lateral portion of nucleus diffusus; nE, nucleus electrosensorius; NPLL, posterior lateral line nerve; OB, olfactory bulb; PEd, dorsal praeeminential nucleus; PGl, lateral preglomerular nucleus; PM, pacemaker nucleus; Tel, telencephalon; TO, optic tectum; SC, spinal cord; VCb, valvula cerebellum; XL, vagal lobe. Scale bar equals $1 \mathrm{~mm}$.

brain sensory and motor areas to be the most diverse portions of the brain.

The model of longitudinal column specialization (model 3) expects structures developing from the dorsally positioned somatic sensory column of the neural tube (e.g., facial lobes, cerebellum, optic tectum) to undergo more evolutionary changes than structures located in the visceral column near the middle of the neuraxis or the more ventrally positioned somatic motor column (Herrick 1891; Ito 1987). Under this model, the most morphologically conservative regions are expected to be located near the middle of long axis of the neural tube. Precise criteria for the assignment of structures to longitudinal columns are detailed by Nieuwenhuys (1998).

The model of sensory drive (model 4) expects that "the evolution of sensory systems, signals, and behavior is coupled such that changes in one suite of traits cause evolutionary changes in the others. These suites of traits must not be expected to evolve independently, they will coevolve" 


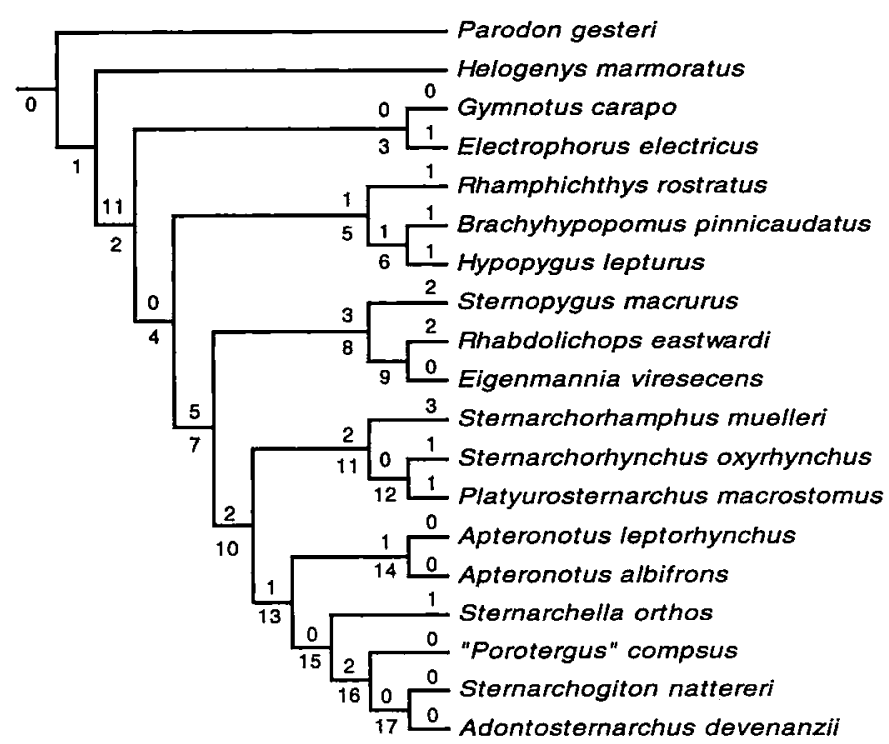

FIG. 3. Phylogenetic interrelationships among 17 gymnotiform species for which volumetric data of brain divisions were examined. Taxonomy and tree topology from Albert and Campos-da-Paz (1998). Node number indicated below, and number of brain steps indicated above each node. A total of 43 unambiguous transformations are plotted. Spatial localization of these steps is summarized in Table 5. Note number of steps differs from that of Figure 1 due to inclusion of fewer taxa.

(Endler 1992, p. 130). This model also expects female preference for male secondary sexual phenotypes to precede the origin of the male trains, and that primary sensory and motor areas to have more steps.

Models of functional plasticity predict that organisms possessing less stereotyped, functionally generalized phenotypes (e.g., morphologies, behaviors, physiological mechanisms) are exposed to a greater range of selection regimes and therefore undergo more anagenetic change.

The model of behavioral plasticity (model 5) predicts that functionally generalized behaviors, that is, those participating in many activities, give rise to behaviors specialized for particular purposes (West-Eberhardt 1989). This model also expects an increase in behavioral variation to precede the origin of morphological specialization. Testing the latter relies on the negative evidence that a behavioral character has evolved without a corresponding morphological change.

Neural plasticity (model 6) proposes that increased variation in neuronal morphology, number, and/or size predates and promotes functional specialization (Meinertzhagen 1989; Barth et al. 1997). Under this model, generalized neural systems are expected to give rise to specialized systems, and more steps are expected in developmentally plastic and/or functionally generalized regions of the nervous system.

The second class of models are those employing constraints to link patterns of organismal design with mechanisms underlying the production of variation (Alberch et al. 1979; Alberch 1980). As such they focus on factors intrinsic to organisms.

Models of functional constraint (model 7) expect neural systems involved in multiple uses to undergo less evolutionary change than neural structures dedicated to a single func- tion (Cohen 1988; Bass and Baker 1991). This expectation derives from the idea that neuronal cell populations involved in many functional systems are too encumbered to specialize for the benefit of any one task.

Models of structural repetition expect the inverse pattern, namely that the number of independent design elements correlates positively with phenotypic diversity (Emerson 1988; Lauder and Liem 1989; Schaefer and Lauder 1996). These models also expect morphological divergence within a population of neurons to precede functional specialization. Two candidate mechanisms are reviewed for the ontogenetic production of structural repetition in the nervous system: parcellation (Ebbesson 1980, 1984) and amplification (Kaas 1982, 1993). The products of these events are serial (iterative) homologues, whether arrayed in an anatomical series or otherwise (Roth 1984, 1991).

Parcellation (model 8) is expected to result in "the development of more stratification in a system . . . involv[ing] greater segregation of inputs from different sources, specialization of neuronal types, and loss of certain connections" (Ebbesson 1980, p. 195). Selective losses of cell types and fasciculation of afferent or efferent fiber bundles will also result in more discrete layers and more sublayers. An expected functional consequence of lamination is that neurons will respond "to a more defined class of stimuli or resolv[e] more accurately within that class" (Ebbesson 1980, p. 197). Parcellation also predicts that serially repeated units are homologous as a group to a single structure in an outgroup taxon (Fig. 4A).

Duplication of cortical maps (Kaas 1982) is an example of amplification (model 9), and has been proposed in the origin of multiple topographic representations (maps) in many vertebrates (Kaas 1991, 1993) including electric fishes (Viete 1991; Gonzalez et al. 1993). Duplication predicts that features of structurally repeated units are similar to one another, and to a single structure in an outgroup taxon (Fig. 4B). Recognition criteria for similarity in neural structures are reviewed by Kaas (1982). The serially arranged products of amplification are also expected to share these similarities with structures in a more remote common ancestor than those of parcellation.

Models of developmental constraint or canalization (model 10) expect features more deeply embedded in epigenetic pathways or developing earlier in ontogeny to vary less, evolve more slowly, and exhibit less phylogenetic diversity (Alberch 1982; Roth et al. 1993). Two mechanisms of canalization in the nervous system are provided by Puelles et al. (1987) and Puelles (1995); small compartment size and proximity to inductive sources reduce the opportunity for developing brain divisions to vary. Canalization expects structures developing under the influence of a single or few developmental cues (e.g., primary medullary sense centers) to exhibit open growth and structures under the influence of multiple developmental cues (e.g., optic tectum, thalamus) to grow asymptotically. Canalization also expects that developmental integration of traits leads to their genetic integration, a coordinated response to selection and, ultimately, correlated patterns of character evolution (Cheverud 1996). Canalization expects ancient epigenetic pathways to be more stereotyped than more recent evolved pathways and therefore to undergo 
TABLE 3. Ten published models of neural evolution and some respective expectations cast in terms of expected sequence (A), correlation (B), spatial localization (C), and functional localization (D) of character-state steps. ${ }^{I}$ Wording of models and expectations not necessarily as expressed in original formulations. PNS, peripheral nervous system; CNS, central nervous system.

I. Specialization (models 1-6)

1. Habitat specialization

2. Neurobiotaxis

3. Longitudinal column specialization

4. Sensory drive

5. Behavioral plasticity

6. Neural plasticity

II. Constraint (models 7-10)

7. Functional constraint

Structural repetition (models 8 and 9)

8. Parcellation

9. Amplification

10. Developmental constraint
(C, D) Structures with higher intraspecific variance have more developmental plasticity, more steps.

(A) Evolutionary change in PNS temporally precedes that of coupled changes in the CNS. (B) Sister species have habitat, behavioral and neuromorphological differences. (C, D) Primary sensory and motor structures have more steps than association structures.

(C, D) Neurons physically closer to physiological stimuli have more steps; sensory and motor structures differ more than other brain structures.

(B) Size of structures in longitudinal columns of neuraxis correlated with functionally coupled structures in sensory-motor periphery. (C, D) Structures developing from dorsal column have most steps; structures developing from middle columns have fewest steps.

(A) Female preference for traits precedes male secondary sexual phenotypes. (B) Evolution of sensory systems, signals, and behaviors are coupled. (C, D) Primary sensory and motor areas have more steps.

(A) Functionally specialized behaviors are derived; increased behavioral variation precedes morphological specialization. (C) More steps in characters coupled to behavioral plasticity.

(A) Functionally specialized neural mechanisms are derived; increased physiological variation precedes morphological divergence. (C) Number of steps correlated with degree of plasticity. (D) More steps in functionally generalized areas.

(C) Structures with less developmental plasticity have fewer steps.

(B) Phylogenetic distributions of functionally integrated traits are more correlated than nonintegrated traits. (D) Functionally specialized neural systems have more steps than those subserving multiple functions.

(A) Metamerism precedes functional specialization. (C) More steps in serially repeated units.

(A) Increased stratification, segregation of inputs, fasciculation of fiber bundles, specialization of neuronal types, loss of connections and cell types, and sensitivity of neurons to defined classes of stimuli are all derived features. (C) Serially repeated units are homologous as a group to a single unit in an outgroup taxon (Fig. 4).

(C) Serially repeated units are homologous with one another, and each with a single unit in an outgroup taxon.

(B) Phylogenetic distributions of developmentally integrated traits are more correlated than nonintegrated traits. (C, D) Features more deeply embedded in epigenetic pathways vary less. Fewer steps in earlier developmental stages, in structures developing from smaller embryonic compartments, in regions in proximity to inductive sources, in structures in more ancient developmental pathways; structures developing under the influence of multiple cues undergo asymptotic growth.

' References for models: (1) Webster 1984; Kotrschal and Palzenberger 1992; (2) Ariens-Kappers et al. 1960; Wilczynski 1984; (3) Herrick 1891; Ito 1987; (4) Endler 1992; (5) West-Eberhardt 1989; (6) Meinertzhagen 1989; Barth et al. 1997; (7) Cohen 1988; Bass and Baker 1991; Models 8 + 9; Lauder and Liem 1989; (8) Ebbesson 1980, 1984; (9) Kaas 1982, 1991; (10) Alberch et al. 1982; Roth et al. 1993; Puelles 1995.

less divergence. Models that do not assume constraints on the production of variation predict that phenotypic diversity, that is, the number of phylogenetic steps, increases proportionately with age.

\section{Assessing Phylogenetic Patterns}

The expectations of the models are expressed in terms of patterns of character-state transformations. Analyses of the total neural character-state diversity were assessed over all the ingroup taxa of Figure 1 and for the brain characters in isolation over the taxa in Figure 3. Numbers of steps in all analyses are restricted to unambiguous character-state changes or steps (S).

Character-state patterns are assessed in terms of the temporal distribution of character states on a cladogram and the physical localization of these changes to regions of an organism. Phylogenetic sequence is the temporal order of different steps on a cladogram, or the polarity of alternative character states (Maddison 1990; Buckup 1993). Character correlation is defined as similarity in patterns of homoplasy among two or more characters greater than expected by chance alone (Höglund 1989; Harvey and Pagel 1991). Patterns of character homoplasy may also be compared with environmental variables (Endler 1995). This use of correlation differs from the method of Maddison (1990), which tests the effect of characters on the probability of change in other characters.

Character localization was assessed against four systems of categorizing neural divisions. Category I divisions are the peripheral and central nervous systems. Category II divisions are conventional dichotomies in the hierarchy of embryonic differentiation (von Baer 1828; Hamburger 1952; Nelsen 1953; Northcutt 1995). Figure 5B illustrates the boundaries of the second- and third-tier embryological brain divisions. The general timing of differentiation and early growth of these divisions is similar in many teleost species (Toyoda and Uematsu 1994; Means and Lannoo 1996; Tomoda and Uematsu 1996). Category III divisions are the longitudinal columns of Herrick (1891). Category IV divisions are the functional units of the sensory-motor arc. Under this clas- 


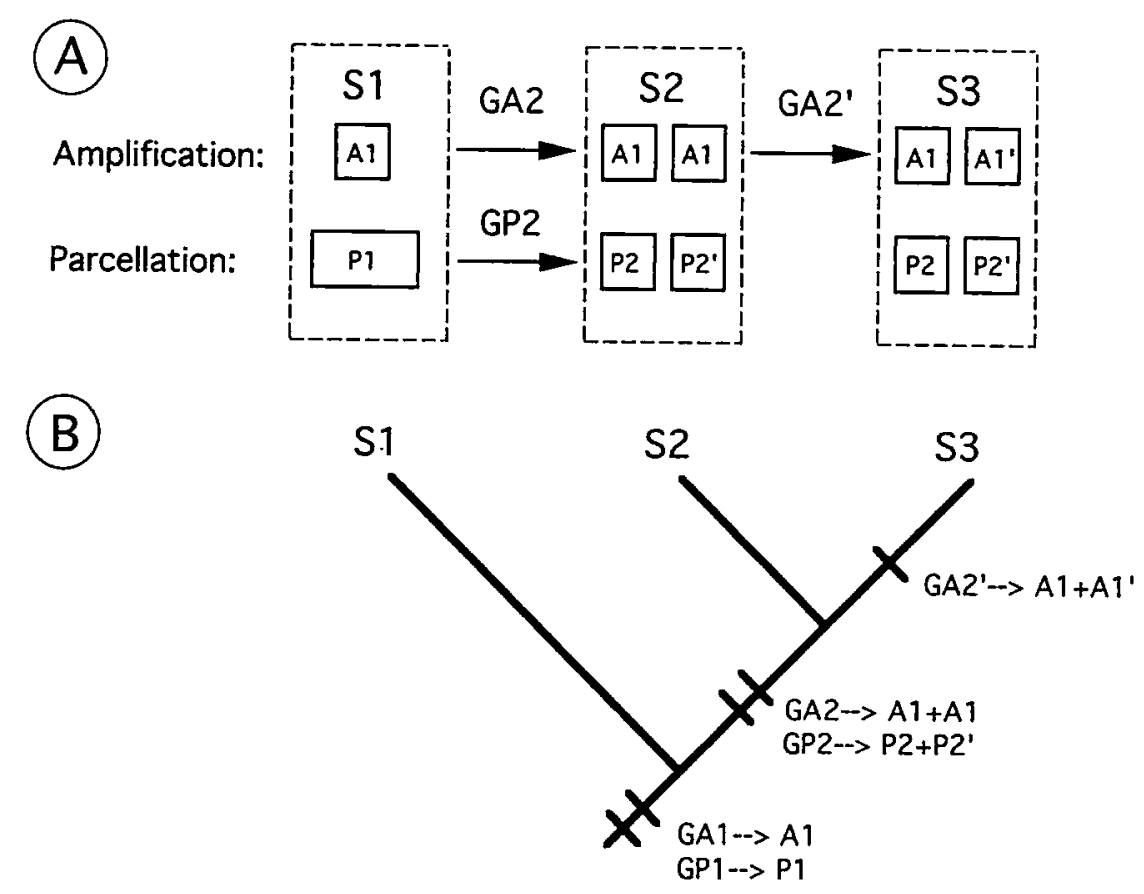

FIG. 4. Consequences of amplification and parcellation as mechanisms generating structural repetition. (A) Alternative scenarios producing serially arranged structures. (B) Cladogram illustrating these events as phylogenetic characters. In the primitive condition, as retained in taxon $S 1$, genetic system GA1 produces the phenotype A1 and GP1 produces P1. Genetic systems GA2 and GP2 produce the serially arranged phenotypes observed in taxa $S 2$ and $S 3$. An additional event GA2' is required to produce the phenotype A1 observed in taxon S3. Note the products of the amplification event GA2 are all Al and are identical with the plesiomorphic phenotype. By contrast, the products of a parcellation event at GP2 are P2 (and/or P2' if P is not homogenous), which differ from the plesiomorphic phenotype. Serially arranged products of amplification share their homologous similarity from a more remote common ancestor than those of parcellation.

sification, sensory and motor functional categories were defined as the primary receptor and effector neurons in the PNS and their immediate source and target neurons in the central nervous system (CNS). Other CNS structures are classified as association areas.

The test of localization is sensitive to biases of character selection due to differential access to or familiarity of otherwise comparable regions. To reduce these sources of error, effort was made to apply equal attention to each of the major regions of the nervous system. Only characters developing from the ectoderm or the neural tube were included in the analysis, excluding characters of the electric organs that develop from mesoderm (Kirschbaum 1983). Characters that could not be localized to individual brain divisions and those that have no documented anatomical location were also excluded (characters 8,18 , and 36). Characters of the outgroups and more inclusive taxa were also excluded to increase the uniformity of sampling within ingroup taxa (characters 17 and 26).

\section{Generating Expected Numbers of Steps}

Regression analyses were used to generate expected numbers of steps localized to each third tier neural division based on two null hypotheses: (1) the number of steps is proportional to the size of neural divisions, as measured by relative volume (\%V); and (2) the number of steps is proportional to complexity, as measured by the relative number of constituent parts $(\% P)$. Standard residuals were used to measure deviations of the relative number of steps $(\% S)$ from the values expected by the null models.

Phylogenetic steps are specified events in a given unit of time and therefore may be expected to follow a Poisson probability distribution; thus a square-root transformation was applied to the data (Felsenstein 1981; Goldman 1994). Plots of residuals from regressions on square roots of $\% S$ $(\mathrm{SQRT} \% S$ ) against $\% V$ and $\% P$ vary in size and sign in a random manner.

Values of $\% V$ and $\% P$ were averaged over the 17 ingroup terminal taxa, assuming they have undergone no change within the internal nodes of the tree. In phylogenetic terms, this means that any differences in $\% V$ or $\% P$ among the terminal taxa are assumed to be autapomorphic, in other words, that there is an effective polychotomy with respect to these features (Felsenstein 1985; Harvey and Pagel 1991). In mechanistic terms, this assumption means that differences in size or complexity of brain divisions have not influenced the opportunity for character-state change. The extent to which this assumption is violated reduces the power of regressions using averaged values of the independent parameters to generate expected values of the dependent parameters.

To test the validity of this assumption, the effect of size on the propensity for character-state change in third-tier brain divisions was examined using an analysis of independent contrasts (Purvis and Rambaut 1995). Differences in the volumes of brain divisions $\left(\Delta V=V_{i}-V_{j}\right)$ were compared with differences in the rates of character-state change $(\Delta S=$ 


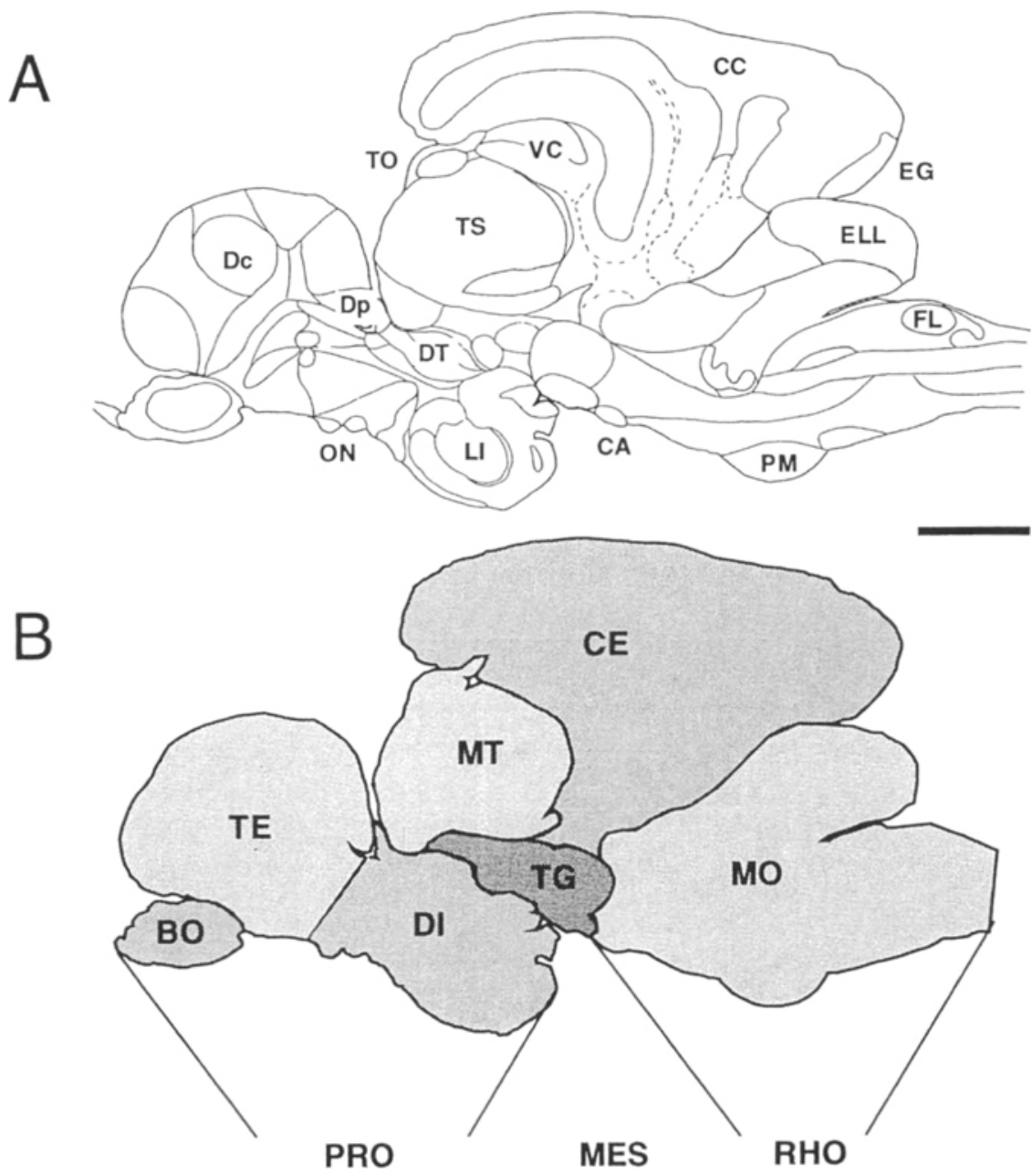

FIG. 5. Drawings of a parasagittal section of the brain of Apteronotus albifrons. (A) Location of structures used in character descriptions (Table 1) or in other parts of the text. (B) Brain regions used in the analysis of character localization. Boundaries of second-tier brain divisions indicated at bottom; regions of differing shading density denote third tier brain divisions. Anterior to left, dorsal to top. Scale bar equals $1 \mathrm{~mm}$. Abbreviations: DT, dorsal thalamus (including nucleus electrosensorius and sublemniscal prepacemaker nucleus); CA, commissure ansulata; CC, corpus cerebellum; Dc, telencephalic area dorsalis centralis; Dp, telencephalic area dorsalis posterior; EG, eminentia granularis; ELL, electrosensory lateral line lobe; FL, facial lobe; ON, optic nerve; PM, pacemaker nucleus; TO, tectum opticum; TS, torus semicircularis; VC, valvula cerebellum. See Figure 2 for location of more laterally positioned structures (e.g., PGl, lateral preglomerular nucleus; NV, trigeminal nerve root).

$\left[S_{i / L i}\right]-S_{j / L j}$ ) for 16 sister taxa $i$ and $j$ (Fig. 3, nodes 2-17), where $V_{z}$ is the volumetric value at terminal taxon or node $z, S z$ the number steps between terminal taxon or node $z$ and the node above it and $L_{z}$ the branch length between terminal taxon or node $z$ and the node above it. Regressions of $\Delta V$ and $\Delta S / L$ were used to assess the assumption that change in the relative volume of brain divisions does not effect the rate of character-state changes (Grafen 1989). Neural volumes of internal nodes were calculated as weighted sums of the values of the two daughter taxa using the equation of standardized linear contrasts:

$$
V_{k}=\left[\left(1 / L_{i}\right) V_{i}+\left(1 / L_{j}\right) V_{j}\right] /\left[1 / L_{i}+1 / L_{j}\right]
$$

where node $k$ indicates the node immediately above nodes $i$ and $j$.

This method of estimating ancestral values makes several explicit assumptions regarding the tempo and mode of character transformation (Felsenstein 1985). Branch lengths for taxa were treated as proportional to the number of species they contain, that is, all terminal taxa are equidistant from the root (Grafen 1989). The use of branch lengths as expected variances follows the Brownian motion model of evolutionary change in which the expected variance of a two-taxon contrast is proportional to the sum of the branch lengths between the taxa and their common ancestor.

Residuals from regressions of SQRT\%S on $\% P$ and $\% V$ were used to compare expected and observed proportions of steps localized to third-tier brain divisions. Standard residual values greater than or equal to 1.0 were coded as 1 , less than or equal to -1.0 coded as -1 , and between -1.0 and 1.0 coded as 0 . For comparison, the qualitative expectations of seven models were coded into integer values, in which 1 represents the expectation of disproportionately many steps, -1 few or no steps, and 0 no expected deviation from the null hypothesis. Matches and mismatches between deviations of observed and expected steps were summed and the fit 
TABLE 4. Localization of neural characters $(C)$ and steps $(S)$ to divisions in four classifications of the nervous system (Categories $I-$ IV). Categories are defined in the text. $\% S_{\mathrm{T}}$, percent total steps; $\% S_{\mathrm{E}}$, percent ectoderm steps; $\% S_{\mathrm{NT}}$, percent neural tube steps. BO, olfactory bulb; CE, cerebellum; CNS, central nervous system; MES, mesencephalon; MO, medulla oblongata; MT, mesencephalic tectum; PNS, peripheral nervous system; PRO, prosencephalon; RHO, rhombencephalon; DI, diencephalon; T1, T2, and T3, first-, second-, and third-tier embryological brain divisions; TE, telencephalon; TG, mesecephalic tegmentum. Data include all characters and steps in Table 1. Because percentages are rounded, totals may not sum to 100 .

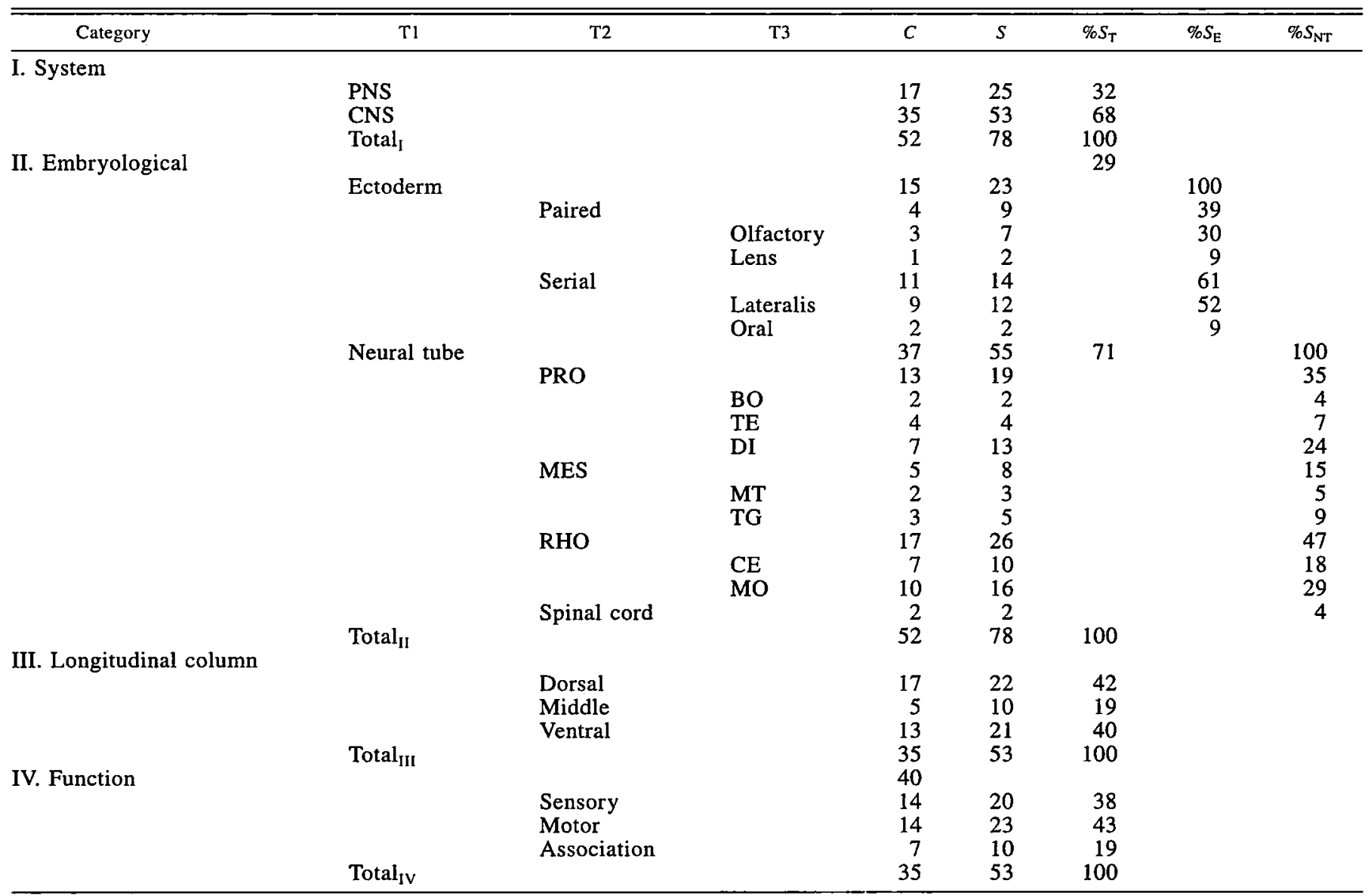

between them decided by a simple majority. Expected patterns were assessed as a match if they agree with the residuals of either $\% P$ or $\% V$.

\section{RESUlts}

\section{Testing Assumptions of Character Localization}

Neural character-state changes are not distributed uniformly over the entire nervous system; certain pairs of comparable tissues and/or functional categories differ substantially in numbers of steps (Table 4). Nevertheless, character-state data from the brain data in isolation are consistent with the several assumptions used in the analysis of character localization. Unlike the neural dataset as a whole, information on the size and complexity of brain divisions is available, which may be used as standards against which to assess the distribution of steps.

The brain data are consistent with assumption that the character sampling was not systematically biased to brain regions of special access or familiarity. Brain divisions studied more intensively by neurophysiological methods did not produce exaggerated numbers of characters or state changes when compared with measures of their size and complexity. The well-studied predominantly electroreceptive centers of the hindbrain, for example, contribute almost one half (49\%) of the total brain state-changes and occupy about $52 \%$ of the total brain volume on average (Table 5). By comparison, the equally well-studied structures of the midbrain contribute only $15 \%$ of the steps while occupying about $24 \%$ of the total brain volume, and the more poorly understood structures of the forebrain contribute $36 \%$ of the steps while occupying a similar $24 \%$ proportion of the total brain volume. Further, the number of named cell groups per unit brain volume may be regarded as an indicator of familiarity, and brain divisions with more recognized parts did not produce exaggerated numbers of state changes. The ratios of $\% P / \% V$ for third-tier brain divisions range from 0.3 to 3.2 , yet possess $\% S$ values of 2.3-32.6 (Table 5).

The gymnotiform neural character data are consistent with the assumptions that changes in size and complexity of thirdtier brain divisions have not significantly influenced the opportunity for character-state change. None of regressions comparing independent contrasts of the volumes of brain divisions $(\Delta V)$ and rates of character-state change $(\Delta S / L)$ over 
TABLE 5. Analysis of character localization in the gymnotiform brain data. Characters of Gymnotiformes (Fig. 3, node 2) excluded. $\% V$, relative volume of brain divisions; $S D$, one standard deviation; numbers (\#) and percentages $(\%)$ of parts $(P)$ and steps $(S)$ localized to embryological brain divisions; $S_{\mathrm{V}}$, residuals from regression of SQRT\%S on $\% V$ (Fig. 6A); $S_{\mathrm{P}}$, residuals from regression of SQRT\%S on $\% P$ (Fig. 6B). Residuals $\geqslant 11.01 \%$ are regarded as different from expected. Residuals for second-tier divisions not reported due to small sample size. Abbreviations of brain divisions as in Table 4.

\begin{tabular}{|c|c|c|c|c|c|c|c|c|}
\hline $\begin{array}{l}\text { Divi- } \\
\text { sion }\end{array}$ & $\% V \pm S D$ & $\# P$ & $\% P$ & $\begin{array}{l}\% P I \\
\% V\end{array}$ & $\# S$ & $\% S$ & $s_{\mathrm{V}}$ & $S_{\mathbf{p}}$ \\
\hline PRO & $23.7 \pm 6.8$ & 68 & 48.2 & 2.0 & 15 & 34.9 & & \\
\hline MES & $23.8 \pm 6.4$ & 30 & 21.3 & 0.9 & 5 & 11.6 & & \\
\hline RHO & $52.6 \pm 10.7$ & 43 & 30.5 & 0.6 & 23 & 53.5 & & \\
\hline BO & $1.4 \pm 0.6$ & 2 & 1.4 & 1.0 & 1 & 2.3 & -0.6 & -0.5 \\
\hline TE & $13.1 \pm 3.7$ & 25 & 17.7 & 1.4 & 4 & 9.3 & -0.2 & -0.6 \\
\hline DI & $9.1 \pm 2.5$ & 41 & 29.1 & 3.2 & 10 & 23.3 & 1.4 & -0.3 \\
\hline MT & $15.7 \pm 4.7$ & 19 & 13.5 & 0.9 & 1 & 2.3 & -1.6 & -1.5 \\
\hline $\mathrm{TG}$ & $8.0 \pm 1.7$ & 11 & 7.8 & 1.0 & 4 & 9.3 & 0.2 & 0.3 \\
\hline CE & $29.7 \pm 6.0$ & 13 & 9.2 & 0.3 & 9 & 20.9 & -0.5 & 1.4 \\
\hline MO & $22.8 \pm 4.7$ & 30 & 21.3 & 0.9 & 14 & 32.6 & 1.1 & 1.2 \\
\hline Total & & 141 & & & 43 & & & \\
\hline
\end{tabular}

the 16 nodes is significant for the seven third-tier brain divisions (for six divisions, $r^{2}<0.1, P>0.2$, and for one division, $r^{2}=0.28, P<0.04$, but slope of regression $\beta<$ 0 ). In other words, character-state changes did not accrue in taxa with relatively larger brain divisions compared with their sister taxa. Among the 35 characters in Table 1 describing diversity in brain morphology, there is a single change in the number of parts (character 14). This is prima facia evidence that changes in complexity of brain divisions did not play a significant role in the accumulation of character-state changes within this group.

\section{Phylogenetic Sequence}

Table 6 summarizes the comparisons of 63 expectations generated by the 10 models of neural evolution with patterns in the gymnotiform neural data. Individual results are referred to Table 6 by method used to assess phylogenetic pattern (columns A-D) and model of neural evolution (rows 1-10).
Numbers of expectations consistent and inconsistent with each model are also listed in Table 6.

Available data on habitat use in gymnotiform species (Schwassmann 1978; Lundberg et al. 1987, 1996) suggest that instances of habitat specialization are no more common than the evolution of generalized habitats. The distribution of habitat utilization (character 8) requires 11 steps, and regardless of optimization method, the sequence of state change is not consistent with two expectations of habitat specialization, namely that generalized habitats and large amounts of habitat variation are plesiomorphic (Table 6, A1). There are six instances in which taxa are optimized as shifting from a generalized habitat (i.e., small streams) to a specialized habitat (i.e., deep channels of large rivers), four instances of reversal, and one instance in which the polarity is ambiguous. Seven species in this analysis are polymorphic for this character and are regarded as exhibiting more variation than taxa inhabiting a single habitat. Of these species, three are inferred to be derived from a stream-dwelling ancestor, three others from a large-river ancestor, and the polarity of this transformation for one species is ambiguous.

Two expectations of neurobiotaxis regarding the sequence of evolutionary change are not observed in gymnotiforms (Table 6, A2). Primary sensory or motor cell groups of the forebrain and hindbrain do not accrue steps before functionally coupled central brain divisions. Also, the derived recurved morphology of electromotoneurons in the electric organ of Sternarchorhamphus (character 46) is located away from the source of stimulation, the pacemaker cells of the hindbrain reticular formation, a primary motor cell group specialized to regulate the rhythmic electric organ discharge (EOD). One expectation of neurobiotaxis is observed in the sequence of change in spherical cells of the electrosensory lateral line lobe (ELL), these cells are primary electrosensory neurons, and the loss of the basilar dendrite of these cells in Sternopygus (character 38) is in the layer of incoming sensory fibers.

The phylogenetic sequence of EOD transformations is generally not consistent with the expectations of sensory drive (Table 6, A4). The motor effectors of the electrosensory sys-

TABLE 6. Comparisons of 63 expectations generated by 10 models of neural evolution, with patterns in character-state changes of the gymnotiform nervous system. Patterns were assessed using four methods: the phylogenetic sequence (column A), correlation (column B), spatial localization (column C), and functional localization (column D), of steps. Numbers in cells indicate expectations consistent (positive) and inconsistent (negative) with each model. Empty cells indicate lack of relevant expectations or data.

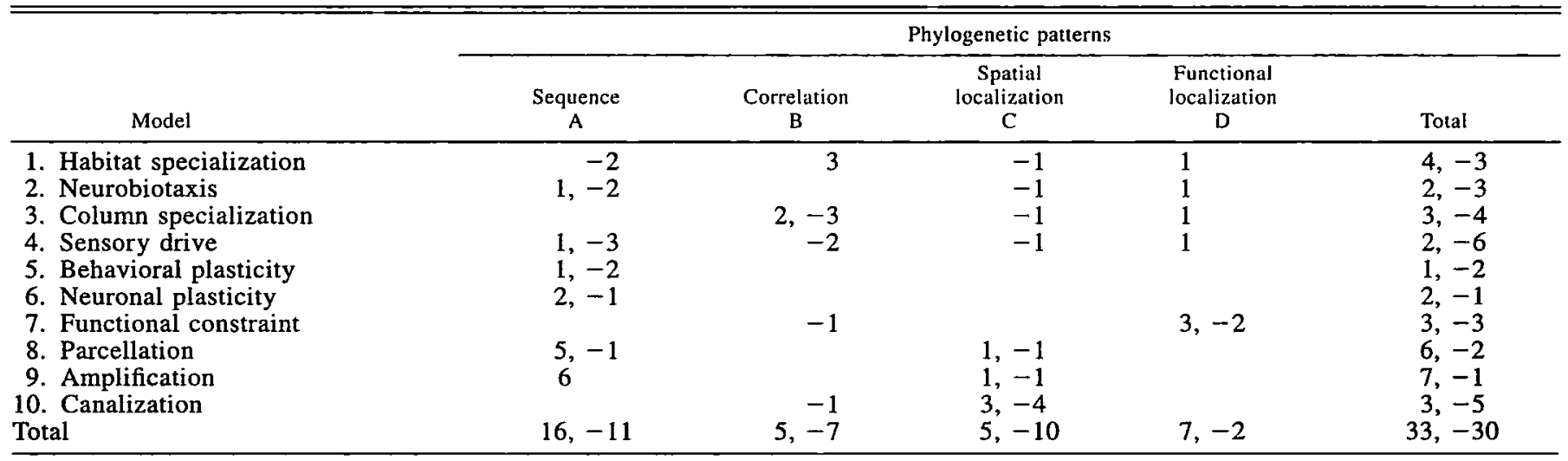


tem are specialized muscle or nerve cells that generate a rhythmic EOD (Bass 1986), and numerous field and laboratory experiments have shown electroreception to participate in both trophic and social interactions (e.g., Black-Cleworth 1970; Hopkins 1972; Hagedorn 1986). Electric fishes have been informally classified as either "wave" or "pulse" species depending on the EOD repetition rate; recent work on gymnotiform systematics has determined the pulse-type EOD to be the plesiomorphic mode (Albert 1999).

Sensory drive expects the evolution of females preference for male EOD frequencies to precede the evolution of these frequencies. In one case (the Sternarchorhynchinae, character 40), female preference for males discharging at higher EOD frequencies does precede the evolution of higher frequencies. However, this pattern is not however observed in the sternopygid taxa Sternopygus and Eigenmannia, in which socially dominant males possess lower EOD frequencies (Hagedorn 1986). There is no evidence that females of pulse-type EOD species prefer males with different repetition rates, either higher or lower than themselves (Hopkins, pers. comm.), as would be expected if female mate selection participated in the origin of the wave-form EOD. There is also no evidence that a female preference for different male EOD frequencies was involved in the origin of gymnotiform active electroreception (Bass 1986).

The phylogenetic sequence of behavioral characters does not lend strong support to the model of behavioral plasticity (Table 6, A5). Instances in which specialized behaviors are derived are no more common than the reverse. For example, Rhabdolichops possesses the derived yet generalized behavior of detecting of prey items in front of the head (character 36, Lannoo and Lannoo 1993). The expectation that generalized behaviors are plesiomorphic is also not observed in the phylogenetic sequence of the jamming avoidance response (JAR, character 21), in which electric fishes shift their EOD frequencies or pulse rates in the presence of electrical interference (see Heiligenberg 1991). The specialized JAR behavior is present in all gymnotiforms except Sternopygus, where the absence is inferred to be derived (Albert and Fink 1996).

The expectations of neural plasticity were observed in at least two instances (characters 41 and 42) of EOD specialization (Table 6, A6). The absence of morphological correlates of the other EOD characters is negative evidence that may be falsified with further study. The irregular EOD of Electrophorus is derived with respect to the highly rhythmic discharges of other gymnotiforms (Black-Cleworth 1970; Rasnow 1994), which does not conform with the prediction that functionally generalized physiological mechanisms are primitive.

Character-state changes in the origin and evolution of the gymnotiform electrosensory system are generally consistent with the two models of structural repetition reviewed. A brief description of the system is provided to clarify these features. Gymnotiformes and its sister taxon, Siluriformes (catfishes), possess low-frequency tuned ampullary-shaped electroreceptor organs, which are used in foraging (passive electroreception, character 17). In Gymnotiformes the ampullary organs project exclusively to the medial segment of the ELL. Gymnotiform fishes also possess high-frequency tuned tuberousshaped organs, which are used in active electroreception, nav- igation, and communication (character 17) and project to the three lateral segments of the ELL. The electrosensory system of gymnotiforms is thus organized into four parallel information processing channels (Carr and Maler 1986), each tuned to different properties of the electrosensory environment (Shumway 1989a,b; Metzner and Heiligenberg 1992; Maler and Mugnaini 1994). These observations are consistent with an expectation of both models of serial repetition reviewed, namely that morphological specialization within a population of neurons will precede functional divergence.

The mechanism of parcellation (Ebbesson 1980, 1984) is consistent with the polarity of five features involved in the formation of the gymnotiform central ascending electrosensory pathway (Table 6, A8). Each of the three neural structures of this system possess more layers, sharper boundaries, and more functionally specialized neurons than do their taxic homologues in catfishes or their serial homologues in the mechanosensory system of gymnotiforms (Tong and Finger 1983; Lannoo and Maler 1990). These specializations appear as discrete layers in histological preparations. In addition, at least some of these changes result from a selective loss of connections, as anticipated by parcellation (Maler and Mugnaini 1994). An additional prediction is satisfied in the functional divergence of the lateral three tuberous ELL segments, in which there is an increased sensitivity of neurons to defined classes of stimuli (Shumway 1989b). The polarity of one transformation, the derived mixing of cells in the pacemaker nucleus of sternopygids and apteronotids (Bass 1986), is inconsistent with the expectation of parcellation (contra Kennedy and Heiligenberg 1994).

The organization of the gymnotiform electrosensory system is consistent with six expectations of amplification (Table 6, A9). The three structures of the ascending electrosensory pathway of the brain possess similar patterns of lamination and connectivity, among themselves and with their serial and taxic homologues in the mechanosensory system of other fishes (Finger et al. 1986). Physiological response properties of neurons in the ampullary and tuberous pathways share many derived similarities (Fortune and Rose 1997); they are organized to form electroreceptive maps of the body surface, and the maps of adjacent structures are arranged as mirror images (Carr and Maler 1986; New and Singh 1994). From tritiated thymidine studies the ampullary ELL map has been shown to develop from a distinct germinal zone and the three tuberous maps from a different common germinal zone (Lannoo et al. 1990). Lannoo et al. (1991) show that pyramidal cells in the ELL ampullary map exhibit transient expression of the zebrin II antigen, like the ELL ampullary map in catfishes. Pyramidal cells in the tuberous segments of the ELL do not express zebrin II at any time during their ontogeny.

\section{Character Correlation}

Several neuromorphological differences are associated with habitat parameters in some hypopomid taxa (Table 6, $B 1)$. Differences in the morphology and function of the EOD have been correlated with water conductivity in Brachyhypopomus (Sullivan et al. 1996). In Steatogenys, sister species with recognized habitat differences possess differences in the morphology of an accessory electric organ located above the 


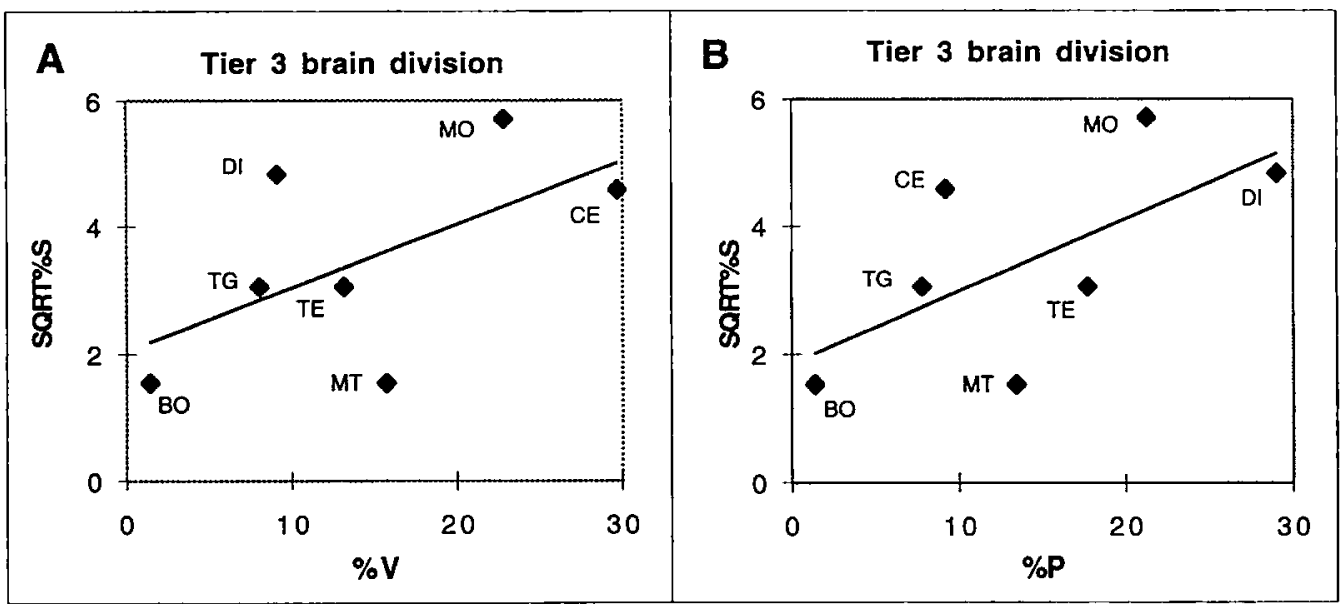

FIG. 6. Regression analyses used to generate expected numbers of steps $(\% S)$ from the relative volume $(\% \mathrm{~V})$ and complexity $(\% P)$ of brain divisions. Square-root values of $\% S(\mathrm{SQRT} \% S$ ) used to sample from a normal distribution (see text). (A, B) Regressions of SQRT\% $S$ on $\% V$ and $\% P$, respectively, for third-tier brain divisions. Equations used to generate residuals in Table 5: $\mathrm{A},(2.0+0.1 \% V), \mathrm{B},(1.9$ $+0.11 \% P)$. Note there is not a strong correlation between steps and volume or parts $\left(\mathrm{A}, r^{2}=0.34 ; \mathrm{B}, r^{2}=0.41\right)$.

pectoral fin, in EOD frequencies (Schwassmann 1978), and in the size of several structures specialized for olfaction and electroreception (e.g., olfactory bulb, corpus cerebellum, ELL). These structures are proportionately larger in the species inhabiting the derived deep-river habitat (Albert, unpubl. data).

Variation in general body shape and meristics has been reported within Eigenmannia in association with habitat variables (Lundberg and Stager 1985; Lundberg et al. 1987), but neuromorphological variation has not been examined. Data on habitat and neuromorphology are not available for the other gymnotiform taxa for whom species-level phylogenies have been proposed (Mago-Leccia et al. 1985; Lundberg and Mago-Leccia 1986; Sullivan 1993; Albert and Miller 1995; Albert and Fink 1996; Albert 1999).

In accord with a prediction of longitudinal column specialization, transformations in the size of the pacemaker nucleus (character 39) and EOD frequencies (character 40) cooccur at three nodes (Table 6, B3), the Apteronotidae, Sternarchorhynchinae, and Sternarchella. Three other neuromorphological observations appear to violate the expectations of longitudinal column specialization. The small optic tectum (character 12) of Rhabdolichops is not accompanied by small eyes, the minute eyes (character 11) of sternarchorhynchine (tube-snouted) apteronotids are not correlated with a reduced optic tectum, and the relatively small cerebellum (character 35 ) of rhamphichthyids and hypopomids is not coupled with a reduction of their lateral line systems. The extent to which the optic tectum and cerebellum participate in other functions (sensory integration and locomotion) reduces the power of these observations as a falsification of longitudinal column specialization.

Contrary to the expectations of sensory drive, most of the changes in the morphology of the electrosensory apparatus are not accompanied by corresponding changes in sensory receptors or behaviors related to mate choice (Table 6, B4). A change in female preference, as assessed by male discharge frequencies (a social dominance parameter) does not accompany the evolution of EOD frequencies in Sternopygidae (Ha- gedorn 1986). The phylogenetic distributions of different sexually dimorphic features of the EOD among closely related species of Apteronotus (Zakon 1986, pers. comm.) and Brachyhypopomus (Sullivan 1993; C. D. Hopkins, pers. comm.) is not coupled. Female choice has been implicated in the evolution of EOD duration (character 43) in Brachyhypopomus pinnicaudatus (Hopkins et al. 1990) and in B. occidentalis in response to playback of different types of waveforms signals (C. D. Hopkins, pers. comm.), yet it remains to be demonstrated in a phylogenetic context.

Data on the ontogeny of electric fishes do not conform with the expectation of functional constraint that the phylogenetic distributions of functionally integrated traits are more correlated than nonintegrated traits (Table 6, B7). Similarly, the data do not support the expectation of canalization that the phylogenetic distributions of developmentally integrated traits are more correlated than nonintegrated traits (Table $6, \mathrm{~B} 10)$. The numerous transformations in structures derived from the lateral line developmental pathway (Lannoo et al. 1990; Vischer et al. 1990; Northcutt 1992; Zakon et al. 1995) exhibit the same mosaic pattern of character evolution as do characters selected from other developmental or functional systems.

\section{Spatial Localization}

Regression analyses of SQRT\%S using $\% V$ and $\% P$ as predictors (Fig. 6) indicate that there may be associations between SQRT\% $S$ and $\% V\left(r^{2}=0.34\right)$ and $\% P\left(r^{2}=0.41\right)$, although neither of these regressions is statistically significant (for $\% V, P=0.17$, for $\% P, P=0.12$ ). These weak associations indicate that neither size nor complexity is a main factor influencing the accumulation of neural characterstate changes within each brain division.

Comparisons of residuals from these regressions with observed proportions of steps localized to third-tier brain divisions are summarized in Table 7 . These data indicate that certain expectations of parcellation and amplification match observed values of character-state diversity, whereas expec- 
TABLE 7. Summary of comparisons between expected and observed proportions of steps localized to third-tier brain divisions. $S_{\mathrm{V}}$, residuals from regression of SQRT\%S on $\% V$ (Fig. 6A); $S_{\mathrm{P}}$, residuals from regression of SQRT\%S on \%P (Fig. 6B). Residuals $\geq 1.0$ coded as 1 , residuals $\leq-1.0$ coded as $-1,1.0>$ residuals $>-1.0$ coded as 0 . Qualitative expectations of Table 3 coded into integer values where 1 represents expectation of disproportionately many steps, -1 few or no steps, and 0 no deviation from the null hypothesis. Abbreviations of brain divisions as in Table 4.

\begin{tabular}{|c|c|c|c|c|c|c|c|c|c|}
\hline \multirow[b]{2}{*}{ Division } & \multirow[b]{2}{*}{$S_{\mathrm{P}}$} & \multirow[b]{2}{*}{$s_{v}$} & \multicolumn{7}{|c|}{ Models } \\
\hline & & & 1 & 2 & 3 & 4 & 8 & 9 & 10 \\
\hline $\mathrm{BO}$ & 0 & 0 & 1 & 1 & 1 & 1 & 0 & 0 & 0 \\
\hline TE & 0 & 0 & -1 & 0 & 1 & -1 & 0 & 0 & 1 \\
\hline DI & 1 & 0 & -1 & -1 & 0 & -1 & 0 & 0 & 0 \\
\hline MT & -1 & -1 & -1 & 1 & 1 & 1 & 1 & 1 & 0 \\
\hline TG & 0 & 0 & -1 & -1 & -1 & -1 & 0 & 1 & -1 \\
\hline $\mathrm{CE}$ & 0 & 1 & -1 & 1 & 1 & -1 & 1 & 1 & 1 \\
\hline MO & 1 & 1 & 1 & 1 & 1 & $\hat{1}$ & 1 & 1 & -1 \\
\hline Matches & & & 2 & 3 & 3 & 1 & 5 & 5 & 2 \\
\hline Mismatches & & & 5 & 4 & 4 & 6 & -1 & 2 & 5 \\
\hline Fit & & & No & No & No & No & Yes & Yes & No \\
\hline
\end{tabular}

tations of habitat specialization, neurobiotaxis, functional column specialization, sensory drive, and canalization do not (Table 6, C1-4 and C8-10).

An expectation common to both models of structural repetition is not observed (Table 6, C8-9), the localization of steps does not correlate positively with the number of independent design elements (Lauder and Liem 1989). Rates of neural evolution in gymnotiforms are not proportional to complexity; brain divisions with more parts per unit volume do not have more steps localized to them.

Patterns of variation within gymnotiform species and of differences between closely related species are consistent with three expectations of developmental constraint (Table $6, \mathrm{C} 10)$. Structures near the ventricles and the junction areas of major brain divisions were found to be the most reliable in assigning transverse sections to homologous levels (Albert 1999). Also, the most pronounced differences within species and between closely related species were observed in germinal zones and areas of developmental cell proliferation (Zupanc and Horschke 1995). These areas are the rostral and caudal poles of the larger lobes (e.g., telencephalon, optic tectum, inferior lobe, cerebellum, electrosensory lateral line lobe). Further in accord with an expectation of developmental constraint, several structures developing under multiple cues (e.g., telencephalon, optic tectum, inferior lobes) follow asymptotic growth curves, achieving similar absolute volumes in mature specimens over a range of body sizes. The sizes of two specialized primary sensory structures, the olfactory bulb and ELL, are correlated with body size, indicating continued growth throughout life (Albert, upubl. data from Steatogenys, Gymnotus, and Apteronotus).

Three expectations of developmental constraint are not observed. Although the hindbrain is the most visibly segmented region of the brain in early embryos (Puelles 1995) it is also the locus of a disproportionate number of steps. Phylogenetic diversity in gymnotiform brain characters is also not associated with proximity to inductive zones. The highly labile pacemaker nucleus of the medulla is not derived from tissues located near a major junction zone of the brain, yet the mid- brain tectum is so derived and is one of the most conservative brain regions. It is likely, however, that the categories used here to localize steps are too coarse to differentiate regions by their proximity to inductive sources.

The phylogenetic age of neural structures in gymnotiforms is poorly correlated with the numbers of steps localized to them. There are many fewer steps localized to the phylogenetically older (craniate) mechanosensory system than to the younger gymnotiform electrosensory system. The electrosensory system is, however, far more massive, occupying much more neural tissue and possessing many more parts. In addition, there are roughly equal numbers of steps localized to the electrosensory structures of the hindbrain of gymnotiforms, which originated approximately 60-80 million years ago (Albert 1999), as there are in the forebrain, which is more than 400 million years old. These two divisions, otherwise matched approximately for size and complexity, have undergone similar amounts of phenotypic evolution in gymnotiform fishes, as measured by numbers of steps (Table 4). This observation is inconsistent with the expectation of canalization that more ancient epigenetic pathways are more stable.

\section{Functional Localization}

In this study, $20(38 \%)$ of the steps in the brain and spinal cord are localized to motor centers, compared with $23(43 \%)$ to primary sensory centers, and $10(19 \%)$ to association centers (Table 4). In gymnotiforms the primary motor centers constitute a much smaller proportion of total neural tube volume than do primary sensory or association centers. In addition, many more steps (23 or $58 \%$ ) are located in the dorsal longitudinal column, compared with $1(3 \%)$ to the middle column and $16(40 \%)$ to the ventral column of the neural tube. These patterns are consistent with certain expectations of habitat specialization, neurobiotaxis, longitudinal column specialization, sensory drive, and functional constraint (Table 6, D1-4, and D7).

Two expectations of functional constraint are observed in the localization of characters (Table 6, D7). Neuronal groups subserving multiple uses possess fewer steps than functionally specialized comparable brain structures. Taken as a whole, there are more steps localized to primary sensory and motor centers than to association areas. The medullary and midbrain reticular formations are, for example, highly conservative in gymnotiforms. The only portion of the reticular formation known to have acquired steps is the pacemaker nucleus. Pacemaker cells are not conservative, and steps localized to this structure (or the electric organ discharge itself) constitute $29 \%$ of the total neural tube steps (Table 4 ). The large amount of evolution observed in the pacemaker cells compared with that of other medullary cells is consistent with the expectation that relaxing functional burden promotes morphological divergence.

The existence of functional constraints is also consistent with the observed conservation of thalamic relay centers, which participate in multiple ascending sensory and descending motor pathways. There are only three steps localized to the 35 thalamic nuclei in the gymnotiform data, which constitute $6 \%$ of the brain total, as compared with $12 \%$ expected 
by their relative complexity and size (standard residual $=$ -1.0 ). Systematic studies examining differences in the connections of thalamic relay centers among gymnotiforms have not been reported, and it is therefore premature to conclude that functional constraints are demonstrated in the thalamus (Striedter 1992; Heiligenberg et al. 1996; Wong 1997).

\section{DISCUSSION}

\section{Performance of Methods for Assessing Phylogenetic Patterns}

Expectations expressed in terms of phylogenetic sequence were invoked by all but three of the models, which is greater than the other methods used to assess phylogenetic patterns. Twenty-seven expectations (or $43 \%$ ) are expressed in terms of sequence, of which $16(50 \%)$ are consistent with the empirical data (Table 6 , column 1). Character correlation proved to be a relatively less applicable method, being germane to 12 expectations (or 19\%) and only five of the 10 models. As a test, however, character correlation is slightly more discriminating than phylogenetic sequence, being consistent with just $42 \%$ ( 5 of the 12 ) proposals.

The localization of steps was employed in the expectations of all 10 models reviewed, and data were recovered pertaining to expectations of eight of these models. There is a lack of data to contrast the localization of characters applying to different levels of structural organization (e.g., physiological vs. behavioral plasticity). As a whole $\mathrm{CL}$ is applicable to 24 (38\%) of the expectations. The spatial localization of steps is employed in the expectations of six of the models, used to test 15 (or 24\%) expectations, and is consistent with five expectations. There are nine expectations (or 14\%) tested by functional localization, which are restricted to the five models invoking explicitly functional expectations. Functional localization is consistent with seven of these nine expectations.

\section{Reviews of the Models}

Is there a single best overall model for neural evolution in gymnotiform fishes? The data recovered from this analysis suggest that there is not. Without exception, the models reviewed were unsuccessful at making global predictions, and more than half of the expectations were found to be consistent with the gymnotiform neural data. Clearly, existing models of neural evolution have been cast in excessively general terms (Butler and Hodos 1996).

Models of specialization were less successful (models 16,14 consistent 19 inconsistent) than models of constraint (models $7-10,19$ consistent, 11 inconsistent). This may be due in part because the methods used to assess models of specialization are less sensitive to features with high population-level variance. These features are more difficult to code and fewer discrete phylogenetic characters may be localized to them. In other words, variable features may be underrepresented as phylogenetic characters, which in turn underestimates the actual contribution of microevolutionary processes to the formation of macroevolutionary patterns. Models of habitat specialization in particular are difficult to assess in gymnotiforms. Demarcating and sampling habitats in the Amazon Basin is arduous and the natural history of many species in this region is poorly known (Goulding et al. 1988; Lowe-McConnell 1991). Models based on constraints may also be better at predicting observed patterns of character evolution because many components of gymnotiform functional design, such as the position and connections of the lateral line nerves and brain centers, are primitive characters shared with other vertebrates (Northcutt 1992). These features do not require a special explanation as design elements in the evolution of the gymnotiform nervous system.

\section{General Patterns}

If the models are not universal, are there certain conditions under which they may apply? Three parameters that may limit the generality of models are examined: properties of characters at particular sizes or spatial scales, of tissues or developmental systems, and of individual taxa. Size-specific models posit that phenotypic changes at different spatial scales are subjected to different physicochemical and biological regularities. Cellular recognition, for example, which is efficacious in coordinating axonal outgrowth, is not expected to govern the formation of complex trophic or foraging systems (Edelman 1987). Of the models reviewed, only neurobiotaxis and parcellation make explicit predictions regarding the evolution of individual neurons. A slim majority of expectations of these models ( 7 of 12 ) are found to be consistent with the gymnotiform neural data.

Tissue specific models posit rules of diversification unique to certain developmental pathways. For example, in many vertebrates the morphology of developing sensory neurons responds to receptor stimulation (Edelman 1987; Ito et al. 1992), and the terminal morphology of electrosensory neurons in gymnotiforms is controlled by differentiating integumental receptor cells (Vischer 1990; Zakon et al. 1995). The morphology of developing skeletal-motor systems, however, is sensitive to physical stress (Smith and Hall 1990; Herring 1993). Models 1-4 enumerate expectations of specific parts. As a group these models are less successful than the models as a whole, being consistent in $36 \%$ (9 of 25) of the tests to which they are germane.

Models of behavioral and neural plasticity and models of constraint expect developmental systems with a high degree of integration (pleiotropy or epistasis) to be phylogenetically more conservative (Lauder et al. 1989; Cheverud 1996). Tissues such as the precordal mesoderm and the junction areas between the major brain divisions participate in multiple inductive networks and are in fact more conservative among vertebrates in general, and this pattern is observed in gymnotiforms (see Results in reference to Table 6, C10). The electroreceptive structures of the hindbrain, however, do exhibit substantial developmental plasticity (Gonzalez et al. 1993) and are yet the locus of numerous steps.

Taxon specific models posit rules governing phenotypic diversification that apply uniquely to individual groups of organisms. Such characters possessing the property to alter the phylogenetic trajectory of a lineage have been referred to "key innovations" (see review by Lauder and Liem 1989). Models of ontogenetic constraint expect taxon-specific mechanisms channeling the direction of evolutionary change. Models of specialization, by contrast, expect that repeatedly 
evolved characters among closely related taxa result from parallel selection acting on homologous structures (Wake 1991). The relative success of models of constraint may indicate that taxon-specific mechanisms do participate in the parallel origins of neural features in gymnotiform fishes.

The relatively poor performance of the models of specialization may also result from real biological differences between variation within species and differences between species (Orr and Coyne 1992). Taxon-specific models expect that evolutionary patterns inferred from the study of younger, less-inclusive clades are less likely to sample low-frequency, high-impact events that structure broader phylogenetic patterns (Stanley 1990). Furthermore, the effects of differential rates of speciation and extinction are amplified when comparing larger clades with more distantly related species.

The paucity of studies examining neuromorphological diversification in other groups of fishes makes it difficult to assess the generality of these results. Comparative data on the cytology and ultrastructure of teleost brains (e.g., Ito et al. 1997; Yoshimoto et al. 1997, 1998) are presently available for too few species to systematically examine the differential effects of spatial scale on character evolution. In some instances, certain localized structural peculiarities are unique to individual taxa, for example, the third ventricular specialization of notothenioid icefishes (Lannoo and Eastman 1995). In other cases, characters of larger scale like the hypertrophied dorsal lobes of sensory systems are distributed homoplastically among widely divergent teleostean taxa (Ito 1987).

These results on the localization of steps differ from those of other studies on teleost fishes. Empirical data on the brains of icefishes (Eastman and Lannoo 1995), minnows (Evans 1952; Marshal and Thines 1958; Miller and Evans 1965; Masai et al. 1982; Kotrschal and Junger 1988; Kotrschal and Palzenberger 1992; Smith 1992), pikes (Means and Lannoo 1996), and cichlids (Huber et al. 1997) indicate that in these teleost groups the most variable regions are primary sensory centers of the medulla (e.g., facial and vagal lobes), the cerebellum, and optic tectum. In adult gymnotiform fishes these areas are important zones of continuing cell proliferation (Zupanc and Horschke 1995), but only the cerebellum accrues disproportionate amounts of character evolution.

The characters examined in this study are distributed in taxa with divergence times ranging from approximately $10^{6}$ $10^{8}$ years. Among 52 species of coral reef fishes possessing similar divergence times and occupying a diverse array of habitats, Bauchot et al. (1989) did not report qualitative differences in features of gross brain morphology, although there are numerous differences in the relative proportions of brain regions (Albert, pers. obs.). Huber et al. (1997) observe substantial differences in the gross morphology of 189 species of African cichlids, lineages thought to represent much shorter divergence times, in the range of $10^{5}-10^{7}$ years. Changes in the connections of brain structures in gymnotiforms are reported by Heiligenberg et al. (1996), in a study of the thalamic prepacemaker system, which controls the electric organ discharge. Differences in the organization and connections of the thalamic relay centers are otherwise known only in more inclusive (older) clades, with divergence times of 1-3 $\times 10^{8}$ years (Striedter 1992, Butler and Northcutt 1993, Albert et al. 1997).

\section{Conclusions}

The external morphology of gymnotiform knifefishes has remained relatively conservative when compared with that of their immediate sister taxon (catfishes), yet gymnotiforms do exhibit sizable phenotypic diversity in the morphology of their neural structures. Within gymnotiforms this diversification does not seem to have resulted in an overall increase or decrease in the size, complexity, or specialization of structures. The $\mathrm{CL}$ analysis permits several conclusions. Evolution in the gymnotiform nervous system is not biased toward the sensory or motor periphery. The characters changes, however, do not appear to be distributed uniformly. Certain tissues provide disproportionate numbers of phylogenetic steps, especially the association areas of the forebrain, the primary sensory and motor centers of the hindbrain, and the lateral line nerves. In addition, the relative sizes of comparable brain divisions do not closely match the number of character-state changes localized to them. This observation is inconsistent with models assuming equal rates of evolution in brain divisions of the same size.

Patterns in the sequence, correlation, and localization of the neural characters examined are consistent with certain expectations of all 10 published models of neural evolution reviewed. The expectations of the models are consistent with more observations than they are inconsistent. The expectations of none of the models were without conflicting data. One of the major conclusions of this study, therefore, is the ease with which current models of neural evolution are matched with observations. Subsequent studies of neural evolution will profit by making more explicit predictions about the phylogenetic consequences of alternative mechanisms.

Taken as a whole, these observations support the views of Northcutt (1992) and Striedter (1992) that neural evolution involves a mosaic of processes operating differentially on functional and developmental systems at different spatial and temporal scales. The methods and data outlined here are offered as a contribution to identifying specific factors responsible for character-state change in the evolution of a vertebrate nervous system.

\section{ACKNOWLEDGMENTS}

We offer out gratitude to J. Eastman, W. Fink, D. Fisher, D. Goldstein, H. Ito, S. Means, P. Myers, G. Northcutt, G. Smith, N. Yamamoto, and M. Zelditsch for their generosity of ideas and useful criticisms of the manuscript. J. Collins and two anonymous reviewers also helped improve the manuscript. We thank C. Carr for sections of the brain of Electrophorus, C. Hopkins for unpublished information regarding female mate choice, and D. Swofford for permission to use the test version of PAUP 4.0. Special thanks to D. Goldstein for ideas on the statistical analyses, and to $S$. Lannoo and M. Yoshimoto for expertise in helping collect the data. Portions of the data reported were collected in the laboratories of H. Ito, G. Northcutt, and R. Davis. This work was also supported in part by National Institute of Health grant 
NS30702-01 to MJL and National Science Foundation grant BSR 9015158 to William L. Fink.

\section{LiTERATURE CiTED}

AlBERCH, P. 1980. Ontogenesis and morphological diversification. Am. Zool. 20:653-667.

- 1982. Developmental constraints in evolutionary processes. Pp. 313-332 in J. T. Bonner, ed. Evolution and development. Springer, New York.

Alberch, P., S. J. Gould, G. F. Oster, And D. B. Wake. 1979. Size and shape in ontogeny and phylogeny. Paleobiology 5:296317.

Albert, J. S. 1999. Phylogenetic systematics of the American knifefishes (Gymnotiformes, Teleostei). Misc. Publ. Mus. Zool. In press.

Albert, J. S., ANd R. Campos-da-Paz. 1998. Phylogenetic systematics of American knifefishes: a review of the available data. In L. Malabarbo, R, E, Reis, R. P. Yari, C. A. S. de Lucena, and Z. M. S. de Lucena, eds. International symposium on phylogeny and classification of Neotropical fishes. In press.

AlBERT, J. S., AND W. L. Fink. 1996. Sternopygus xingu, a new species of electric fish from South America (Teleostei: Gymnotoidei), with comments on the phylogenetic position of Sternopygus. Copeia 1996:85-102.

AlberT, J. S., AND R. R. Miller. 1995. Gymnotus maculosus, a new species of electric fish from Middle America (Teleostei: Gymnotoidei), with a key to the species of Gymnotus. Proc. Biol. Soc. Wash. 108:662-678.

Albert, J. S., M. Yoshimoto, N. Yamamoto, N. Sawal, and H. ITO. 1997. Thalamotelencephalic visual pathways in the sturgeon Acipenser. P. 72 in Xu Qunyuan, ed. XIVth international symposium on morphological sciences. International Academic Publishers. Beijing.

Albert, J. S., R. Froese, and R. Bauchot. 1999. Diversity of brain size in fishes: preliminary analysis of a database including 1174 species in 45 orders. Proc. 5th Indo-Pacific Fish Conference, Noumea, New Caledonia. In press.

Alves-Gomes, J. A., G. Orti, M. Haygood, A. Meyer, and W. Heiligenberg. 1995. Phylogenetic analysis of the South American electric fishes (Order Gymnotiformes) and the evolution of their electrogenic system: a synthesis based on morphology, electrophysiology, and mitochondrial sequence data. Mol. Biol. Evol. 12:298-318.

Ariens-Kappers, C. U., G. C. Huber, And E. C. Crosby. 1960. The comparative anatomy of the nervous system of vertebrates, including man (original 1936). Hafner, Cambridge, U.K.

Barth, M., H. V. B. Hirsch, I. A. Meinertzhagen, and M. HeiSENBERG. 1997. Experience-dependent developmental plasticity in the optic lobe of Drosophila melanogaster. J. Neurol. Sci. 17: 1493-1504.

Bass, A. H. 1986. Electric organs revisited. Pp. 13-70 in T. H. Bullock and W. Heiligenberg, eds. Electroreception. Wiley-Interscience, New York.

BASS, A. H., AND R. BAKER. 1991. Evolution of homologous vocal control traits. Brain, Behav. Evol. 38:240-254.

BATESON, W. 1894. Materials for the study of variation: treated with especial regard to discontinuity in the origin of species. Reprint 1992. Johns Hopkins Univ. Press, Baltimore, MD.

Bauchot, R., J. M. Ridet, AND M. L. BAuChOt. 1989. The brain organization of butterflyfishes. Environ. Biol. Fishes 25:205219.

Black-Cleworth, P. 1970. The role of electrical discharges in the non-reproductive social behavior of Gymnotus carapo (Gymnotidae, Pisces). Anim. Behav. Monogr. 3:1-77.

BREMER, K. 1988. The limits of amino acid sequence data in angiosperm phylogenetic reconstruction. Evolution 42:795-803.

Buckup, P. A. 1993. Phylogenetic interrelationships and reductive evolution in neotropical characidiin fishes (Characiformes, Ostariophysi). Cladistics 9:305-341.

BUTLER, A. B., AND W. Hodos. 1996. Comparative vertebrate neuroanatomy. Wiley-Liss, New York.

Butler, A. B., AND R. G. NorthCUTT. 1993. The diencephalon of the Pacific herring, Clupea harengus: cytoarchitectonic analysis. J. Comp. Neurol. 328:527-546.

CARR, C. E., AND L. MALER. 1986. Electroreception in gymnotiform fish: central anatomy and physiology. Pp. 319-374 in T. H. Bullock and W. Heiligenberg, eds. Electroreception. WileyInterscience, New York.

CArTmILL, M. 1981. Hypothesis testing and phylogenetic reconstruction. Z. Zool. Syst. Evolutionsforsch 19:73-96.

Cheverud, J. 1996. Developmental integration and the evolution of pleiotropy. Am. Zool. 36:44-50.

Cheverud, J., M. M. Dow, AND W. Leutenegger. 1985. The quantitative assessment of phylogenetic constraints in comparative analyses: sexual dimorphism in body weight among primates. Evolution 39:1335-1351.

CoHEN, A. H. 1988. Evolution of the vertebrate central pattern generator for locomotion. Pp. 129-166 in A. H. Cohen, S. Rossignol, and S. Grillner, eds. Neural control of rhythmic movements in vertebrates. Wiley, New York.

EASTMAN, J. T., AND M. J. LANNOO. 1995. Diversification of brain morphology in Antarctic notothenioid fishes: basic descriptions and ecological considerations. J. Morphol. 222:1-37.

EbBEsson, S. O. 1980. The parcellation theory and its relation to interspecific variability in brain organization, evolutionary and ontogenetic development, and neuronal plasticity. Cell Tissue Res. 213:179-212.

. 1984. Evolution and ontogeny of neural circuits. Behav. Brain Sci. 7:321-366.

Edelman, G. M. 1987. Neural Darwinism: the theory of neuronal group selection. Basic Books, New York.

ElLIS, M. M. 1913. The gymnotid eels of tropical America. Mem. Carnegie Mus. 6:109-195.

EMERSON, S. 1984. Morphological variation in frog pectoral girdles: testing alternatives to a traditional adaptive explanation. Evolution 38:376-388.

_ 1988. Testing for historical patterns of change: a case study with frog pectoral girdles. Paleobiology 14:174-186.

ENDLER, J. 1992. Signals, signal conditions, and the direction of evolution. Am. Nat. 139:S125-153.

- 1995. Multiple-trait coevolution and environmental gradients in guppies. Trends Ecol. Evol. 10:22-29.

Evans, H. E. 1952. The correlation of brain pattern and feeding habits in four species of cyprinid fishes. J. Comp. Neurol. 97: 133-142.

Felsenstein, J. 1981. Evolutionary trees from DNA sequences: a maximum likelihood approach. J. Mol. Evol. 17:368-376.

. 1985. Phylogenies and the comparative method. Am. Nat. 125:1-15.

Finger, T. E., C. C. Bell, and C. E. Carr. 1986. Comparisons among electroreceptive teleosts: why are electrosensory systems so similar? Pp. 465-481 in T. H. Bullock and W. Heiligenberg, eds. Electroreception. Wiley, New York.

FINK, S. V., AND W. L. FINK. 1981. Interrelationships of ostariophysan fishes (Teleostei). Zool. J. Linn. Soc. 72:297-353.

. 1996. Interrelationships of ostariophysan fishes (Teleostei). Pp. 209-249 in M. Stiassney, L. R. Parenti, and G. David Johnson, eds. Interrelationships of fishes. Academic Press, New York.

FINK, W. L. 1982. The conceptual relationship between ontogeny and phylogeny. Paleobiology 8:254-264.

Finlay, B. L., K. C. WiKLer, and D. R. Sengelaub. 1987. Regressive events in brain development and scenarios for vertebrate brain evolution. Brain Behav. Evol. 30:102-117.

FISHER, R. A. 1958. The genetical theory of natural selection. $2 \mathrm{~d}$ ed. Dover Press, New York.

ForTUNE, E. S., AND G. J. RoSE. 1997. Temporal filtering properties of ampullary electrosensory neurons in the torus semicircularis of Eigenmannia: evolutionary and computational implications. Brain Behav. Evol. 49:312-323.

Garland, T., JR., P. H. Harvey, and A. R. Ives. 1992. Procedures of the analysis of comparative data using phylogenetically independent contrasts. Syst. Biol. 41:18-32.

GARSTANG, W. 1922. The theory of recapitulation: a critical re- 
statement of the biogenetic law. Zool. J. Linn. Soc. Lond. 35: 81-101.

Goldman, N. 1994. Variance to mean ratio, $R(t)$, for Poisson processes on phylogenetic trees. Mol. Phylogenet. Evol. 3:230-239.

Gonzalez, L., C. Shumway, J. Morissetre, AND J. Bower. 1993. Developmental plasticity in cerebellar tactile maps: fractured maps retain a fractured organization. J. Comp. Neurol. 332:487498.

Goulding, M., M. L. Carvalho, and E. G. Ferreira. 1988. Rio Negro, rich life in poor waters. SPB Academic Publishing, The Hague, The Netherlands.

Grafen, A. 1989. The phylogenetic regression. Philo. Trans. R. Soc. Lond. B Biol. Sci. 326:119-157.

HAGEDORN, M. 1986. The ecology, courtship, and mating of gymnotiform electric fish. Pp. 497-525 in T. H. Bullock and W. Heiligenberg, eds. Electroreception. Wiley, New York.

Hamburger, V. 1952. Development of the nervous system. Ann. N.Y. Acad. Sci. 55:117-132.

Harvey, P. H., AND M. D. Pagel. 1991. The comparative method in evolutionary biology. Oxford Univ. Pess, Oxford, U.K.

HAYES, J. P., AND T. GARLAND. 1995. The evolution of endothermy: testing the aerobic capacity model. Evolution 49:836-847.

Heiligenberg, W. F. 1991. Neural nets in electric fish. MIT Press, Cambridge, MA.

Heiligenderg, W. F., W. Metzner, C. J. H. Wong, and C. H. KELLER. 1996. Motor control of the jamming avoidance response of Apteronotus leptorhynchus: evolutionary changes of a behavior and its neuronal substrates. J. Comp. Physiol. A 179: 653-674.

Hennig, W. 1966. Phylogenetic systematics. Univ. of Illinois Press, Urbana.

HerRICK, C. L. 1891. Studies on the brains of some North American fresh-water fishes. J. Comp. Neurol. 1:228-245.

HerRing, S. W. 1993. Epigenetic and functional influences on skull growth. Pp. 153-206 in J. Hanken and B. K. Hall, eds. Development of the skull. Vol 1. University of Chicago Press, Chicago.

Höglund, J. 1989. Size and plumage dimorphism in lek-breeding birds: a comparative analysis. Am. Nat. 134:72-87.

HopKINS, C. D. 1972. Sex differences in electric signaling in an electric fish. Science 176:1035-1037.

Hopkins, C. D., N. C. Comfort, J. Bastian, ANd A. Bass. 1990. Functional analysis of sexual dimorphism in an electric fish, Hypopomus pinnicaudatus, order Gymnotiformes. Brain Behav. Evol. 35:350-367.

Huber, R., M. J. van StaAden, L. S. Kaufman, and K. F. Liem. 1997. Microhabitat use, trophic patterns, and the evolution of brain structure in African cichlids. Brain Behav. Evol. 50:167182.

Huelsenbeck, J. P., AND B. Rannala. 1997. Phylogenetic methods come of age: testing hypotheses in an evolutionary context. Science 276:227-232.

ITO, H. 1978. A catalogue of histological preparations of the teleost brains. Med. J. Osaka Univ. 28:219-228.

. 1987. Evolution of the brain and a new standpoint of comparative neurology. J. Nippon Med. School 54(4):10-20.

Ito, H., T. Murakami, T. K. FuKuoka, and R. Kishida. 1986. Thalamic fiber connections in a teleost (Sebastiscus marmoratus): visual, somatosensory, octavolateral, and cerebellar relay region to the telencephalon. J. Comp. Neurol. 250:215-227.

Ito, H., M. Yoshimoto, H. UChIYAma, H. SomiYa, AND K. NeGishi. 1992. Changes in retinal ganglion cell morphology after unilateral enucleation in the common carp. Brain Behav. Evol. 40: 197-208.

Ito, H., M. Yoshimoto, J. S. Albert, Y. Yamane, N. Yamamoto, N. Sawai, and A. Kaur. 1997. Terminal morphology of two branches arising from a single stem-axon of pretectal (PSm) neurons in the common carp Cyprinus carpio (Teleostei: Cypriniformes). J. Comp. Neurol. 378:379-388.

KAAS, J. H. 1982. The segregation of function in the nervous system: why do sensory systems have so many subdivisions? Contrib. Sens. Physiol. 7:201-240.

. 1991. Plasticity of sensory and motor maps in adult mammals. Annu. Rev. Neurosci. 14:137-167.
1993. Evolution of multiple areas and modules within neocortex. Pp. 101-107 in P. Levitt and D. O'Leary, eds. Perspectives in developmental neurobiology. Gordon and Breach, London.

197. The evolution of isocortex. Brain Behav. Evol. 46: 187-196.

KenNedy, G., AND W. Herligenberg. 1994. Ultrastructural evidence of GABA-ergic inhibition and glutaminergic excitation in the pacemaker nucleus of the gymnotiform fish, Hypopomus. J. Comp. Physiol. A 174:267-280.

KirschbauM, F. 1983. Myogenic electric organ precedes the neurogenic organ in apteronotid fish. Naturwissenchaften 70:205207.

2_. 1994. Reproduction and development in mormyriform and gymnotiform fishes. Pp. 267-301 in P. Moller, ed. Electric fisheshistory and behavior. Fish and Fisheries Ser., Chapman and Hall, London.

Kotrschal, K., AND H. Junger. 1988. Patterns of brain morphology in mid-European Cyprinidae (Pisces, Teleostei): a quantitative histological study. J. Hirnforschung 29:341-352.

Kotrschal, K., and M. Palzenberger. 1992. Neuroecology of cyprinids, quantitative histology reveals diverse brain patterns. Environ. Biol. Fishes 33:135-152.

LANNOO, M. J., AND J. T. EASTMAN. 1995. Periventricular morphology in the diencephalon of Antarctic notothenioid teleosts. J. Comp. Neurol. 361:95-107.

LANNOO, M. J., AND S. J. LANNOO. 1993. Why do electric fish swim backwards? An hypothesis based on gymnotiform foraging behavior interpreted through sensory constraints. Environ. Biol. Fishes 36:157-165.

LANNOO, M. J., AND L. MALER. 1990. Interspecific variation in the projection of primary afferents onto the electrosensory lateral line lobe of weakly electric teleosts: different solutions to the same mapping problem. J. Comp. Neurol. 294:153-160.

Lannoo, M. J., H. A. Vischer, AND L. Maler. 1990. Development of electrosensory nervous system of Eigenmannia (Gymnotiformes). II. The electrosensory lateral line lobe, midbrain, and cerebellum. J. Comp. Neurol. 294:37-58.

Lannoo, M. J., G. Brochu, L. Maler, and R. Hawkes. 1991. Zebrin II immunoreactivity in the rat and the weakly electric teleost Eigenmannia (Gymnotiformes) reveals three modes of Purkinje cell development. J. Comp. Neurol. 309:1-19.

LAUDER, G. V. 1990. Functional morphology and systematics: studying functional patterns in an historical context. Annu. Rev. Ecol. Syst. 21:317-340.

LAUDER, G. V., AND K. F. LIEM. 1989. The role of historical factors in the evolution of complex organismal functions. Pp. 63-78 in D. B. Wake and G. Roth, eds. Complex organismal functions: integration and Evolution in Vertebrates. Wiley, New York.

Lauder, G. V., A. W. Crompton, C. Gans, J. Hanken, K. F. Liem, W. O. Maier, A. Meyer, R. Presley, O. C. Rieprel, G. Roth, D. SCHLUTER, AND G. A. ZwEERs. 1989. Group report. How are feeding systems integrated and how have evolutionary innovations been introduced? Pp. 97-115 in D. B. Wake and G. Roth, eds. Complex organismal functions: integration and evolution in vertebrates. Wiley, New York.

Leviron, A. E., R. H. Gibbs, JR., E. Heal, AND C. E. Dawson. 1985. Standards in herpetology and ichthyology. Part I. Standard symbolic codes for institutional resource collections in herpetology and ichthyology. Copeia 1985:802-832.

Lowe-MCConNELL, R. H. 1991. Ecological studies In tropical fish communities. Cambridge Univ. Press, Cambridge, U.K.

Lundberg, J. G., AND F. MAGo-Leccia. 1986. A review of Rhabdolichops (Gymnotiformes, Sternopygidae), a genus of South American freshwater fishes, with descriptions of four new species. Proc. Acad. Natl. Sci. Phila. 138:53-85.

LundBerg, J. G., AND C. STAGER. 1985. Microgeographic morphological yariation in the Venezuelan knife-fish Eigenmannia macrops (Gymnotiformes, Sternopygidae). Environ. Biol. Fishes 13(3): $173-181$

Lundberg, J. G., W. M. Lewis, J. F. Saunders, and F. MagoLECCIA. 1987. A major food web component in the Orinoco 
River channel: evidence from planktivorous electric fishes. Science 237:81-83.

LundberG, J. G., C. C. Fernandes, J. S. Albert, and M. Garcia. 1996. Magosternarchus, a new genus with two new species of electric fish (Gymnotiformes: Apteronotidae) from the Amazon River Basin, South America. Copeia 1996:657-670.

MADDISON, W. P. 1990. A method for testing the correlated evolution of two binary characters: are gains or losses concentrated on certain branches of a phylogenetic tree. Evolution 44:539557.

MAGO-LECCIA, F. 1994. Electric fishes of the continental waters of America. Biblioteca de la Academia de Ciencias Fisicas, Matematicas, y Naturales, Caracas, Venezuela. 29:1-206.

Mago-Leccia, F., J. G. Lundberg, AND J. N. Baskin. 1985. Systematics of the South American freshwater genus Adontosternarchus (Gymnotiformes, Apteronotidae). Contributions in Science, Natural History Museum, Los Angeles County, 358:1-19.

Maler, L., AND E. Mugnaini. 1994. Correlating gamma-aminobutyric acidergic circuits and sensory function in the electrosensory lateral line lobe of a gymnotiform fish. J. Comp. Neurol. 345:224-252.

MALER, L., E. SAS, S. Johnston, AND W. Ellis. 1990. An atlas of the brain of the electric fish Apteronotus leptorhynchus. J. Chem. Neuroanat. 4:1-38.

MARShAL, N. B., AND G. L. Thines. 1958. Studies of the brain, sense organ and light sensitivity of a blind cave fish (Typhlogarra widdowsoni) from Iraq. Proc. Zool. Soc. Lond. 131:441-456.

Masai, H., K. Takatsuj, Y. Sato, and Y. Ojima. 1982. Morphological variation in crucian brains, with special reference to the origin of the goldfish. Sonderdruck aus Z.f. zool. Sytematik u. Evolutionsforschung 20:296-301.

Maynard-Smith, J., R. Burian, S. Kauffman, P. Alberch, J. Campbell, B. Goodwin, R. LANDE, D. Raup, AND L. Wolpert. 1985. Developmental constraints and evolution. Q. Rev. Biol. 60:265-287.

MAYR, E. 1960. The emergence of evolutionary novelties. Pp. 349380 in S. Tax, ed. The evolution of life. Univ. of Chicago Press, Chicago.

MCSHAE, D. W. 1996. Metazoan complexity and evolution: is there a trend? Evolution 50:477-492.

Means, S., and M. J. Lannoo. 1996. Patterns and processes of brain diversification within esociform teleosts. J. Morphol. 228: $1-35$.

MeineRTZhagen, I. A. 1989. Fly photoreceptor synapses: their development, evolution, and plasticity. J. Neurobiol. 20:276294.

Metzner, W., and W. H. Heiligenberg. 1992. The coding of signals in the gymnotiform fish Eigenmannia: from electroreceptors to neurons in the torus semicircularis of the midbrain. J. Comp. Physiol. A 169:135-150.

Miller, R. J., AND H. E. Evans. 1965. External morphology of the brain and lips in catostomid fishes. Copeia 1965:467-487.

Nelsen, O. E. 1953. Comparative embryology of the vertebrates. The Blakiston Company, New York.

New, J. G., AND S. Singh. 1994. Central topography of anterior lateral line nerve projections in the channel catfish, Ictalurus punctatus. Brain Behav. Evol. 43:34-50.

NiEUwenhuYs, R. 1998. Morphogenesis and central structure. Pp. 159-228 in R. Nieuwenhuys, H. J. Ten Donkelaar, and C. Nicholson. The central nervous system of vertebrates, Springer, Berlin.

Nieuwenhuys, R., H. J. Ten DonkelaAR, and C. Nicholson. 1998. The meaning of it all. Pp. 2135-2196 in R. Nieuwenhuys, H. J. Ten Donkelaar, and C. Nicholson. The central nervous system of vertebrates, Springer, Berlin.

Nishikawa, K. C. 1987. Staining amphibian peripheral nerves with Sudan Black B: Progressive vs. regressive methods. Copeia 1987:489-491.

NODEN, D. M. 1991. Vertebrate craniofacial development-the relationship between ontogenetic processes and morphological outcome. Brain Behav. Evol. 38:190-225.

NoRTHCUTT, R. G. 1992. The phylogeny of octavolateralis ontogenies: a reaffirmation of Garstang's phylogenetic hypothesis. $\mathrm{Pp}$.
21-47 in D. B. Webster, R. R. Fay, and A. N. Popper, eds. The evolutionary biology of hearing. Springer-Verlag, New York.

. 1995. The forebrain of gnathostomes: in search of a morphotype. Brain, Behav. Evol. 46:275-318.

NoRTHCUTT, R. G., AND M. R. BRAFORD, JR. 1980. New observations on the organization and evolution of the telencephalon of actinopterygian fishes. Pp. 41-98 in S. O. E. Ebbesson, ed. Comparative neurology of the telencephalon. Plenum Publishing, New York.

OMLAND, K. E. 1997. Correlated rates of molecular and morphological evolution. Evolution 51:1381-1393.

ORR, H. A., AND J. A. COYNe. 1992. Genetics of adaptation. Am. Nat. 140:725-742.

Patterson, C. 1982. Morphological characters and homology. Pp. 21-74 in K. A. Josey and A. E. Friday, eds. Problems in phylogenetic reconstruction. Academic Press, London.

PrUM, R. O. 1990. Phylogenetic analysis of the evolution of display behavior in the Neotropical manakins (Aves: Pipridae). Ethology 84:202-231.

Puelles, L. 1995. A segmental morphological paradigm for understanding vertebrate forebrains. Brain Behav. Evol. 46:319337.

Puelles, L., J. A. Amat, and M. Martinez-De-La-Torre. 1987. Segment-related, mosaic neurogenetic pattern in the forebrain and mesencephalon of early chick embryos. I. Topography of ACHe-positive neuroblasts up to stage HH18. J. Comp. Neurol. 266:247-268.

Purvis, A., AND A. Rambaut. 1995. Comparative analysis by independent contrasts (CAIC): an Apple Macintosh application for analyzing comparative data. Computer Appl. Biosci. 11:247251.

RASNOw, B. 1994. The electric field of a weakly electric fish. Ph.D. diss., California Institute of Technology, Pasadena, CA.

RIDLEY, M. 1983. The explanation of organic diversity: the comparative method and adaptations for mating. Oxford Univ. Press, Oxford, U.K.

Rose, G. J., AND J. C. CANFIELD. 1993. Longitudinal tracking responses of Eigenmannia and Sternopygus. Pp. 698-700 in C. C. Bell, C. D. Hopkins, and K. Grant, eds. Contributions of electrosensory systems to neurobiology and neuroethology. Proceedings of a conference in honor of the scientific career of Thomas Szabo. J. Comp. Physiol. A. Vol. 173.

Roth, G., C. Naujoks-Manteuffel, and K. C. Nishikawa. 1992. How do ontogeny, morphology, and physiology of sensory systems constrain and direct the evolution of amphibians? Am. Nat. 139:S105-S124.

Roth, G., K. C. Nishikawa, C. Naujoks-ManteufFel, A. SCHMidt, AND D. B. WAKE. 1993. Paedomorphosis and simplification in the nervous system of salamanders. Brain Behav. Evol. 42:137170.

Roth, L. 1984. On homology. Biol. J. Linn. Soc. 22:13-29.

1991. Homology and hierarchies: problems solved and unresolved. J. Evol. Biol. 4:167-194.

SCHAEFER, S. A., AND G. V. LAUDER. 1996. Testing historical hypotheses of morphological change: biomechanical decoupling in loricariod catfishes. Evolution 50:1661-1675.

Schnitzlein, H. N. 1977. The telencephala of Division I of the teleost fishes. J. Hirnforschung 18:157-178.

SchwassmanN, H. O. 1978. Times of annual spawning and reproductive strategies in Amazonian fishes. Pp. 187-200 in J. E. Thorpe, ed. Rhythmic activities of fishes. Academic Press, London.

SHumway, C. A. 1989a. Multiple electrosensory maps in the medulla of weakly electric gymnotiform fish. I. Physiological differences. J. Neurosci. 9:4388-4399.

. 1989b. Multiple electrosensory maps in the medulla of weakly electric gymnotiform fish. II. Anatomical differences. J. Neurosci. 9:4400-4415.

SMith, G. R. 1992. Phylogeny and biogeography of the Catostomidae, freshwater fishes of North America and Asia. Pp. 778-826 in R. L. Mayden, ed. Systematics, historical ecology, and North American freshwater fishes. Stanford Univ. Press, Stanford, CA. Smith, M. S., AND B. K. HALL, 1990. Development and evolu- 
tionary origins of vertebrate skeletogenic and ontogenetic tissues. Biol. Rev. 65:277-373.

Sober, E. 1988. Reconstructing the Past. MIT Press, Cambridge, MA.

SoREnson, M. D. 1996. TreeRot. Univ. of Michigan Press, Ann Arbor.

STANLEY, S. M. 1990. Adaptive radiation and macroevolution. Pp. 1-15 in P. D. Taylor and G. P Larwood eds. Major evolutionary radiations. Clarendon Press, Oxford, U.K.

Striedter, G. F. 1992. Phylogenetic changes in the connections of the lateral preglomerular nucleus in ostariophysan teleosts: a pluralistic view of brain evolution. Brain Behav. Evol. 39:329357.

Sullivan, J. P. 1993. Diversity of the Neotropical electric knifefish family Hypopomidae (Gymnotiformes). Abstract. P. 163 in Proc. Am. Soc. Ichthyol. Herpetol. Austin, TX.

Sullivan, J. P., C. D. Hopkins, AND N. C. Comfort. 1996. Water conductivity as an invisible barrier to dispersal in South American freshwater for hypopomid electric fishes. Abstract. P. 292 in Proc. Am. Soc. Ichthol. Herpetol., New Orleans, LA.

SWOFFORD, D. L. 1993. PAUP: phylogenetic analysis using parsimony. Vers. 3.1.1. Computer program distributed by the Illinois Natural History Survey, Champaign, IL.

TAYLOR, W. R., AND G. C. VAN DYKE. 1985. Revised procedures for staining and clearing small fishes and other vertebrates for bone and cartilage study. Cybium 9:107-119.

TOMODA, H., AND K. UEMATSU. 1996. Morphogenesis of the brain in larval and juvenile Japanese eels Anguilla japonica. Brain Behav. Evol. 47:22-41.

TONG, S. L., AND T. E. FINGER. 1983. Central organization of the electrosensory lateral line system in bullhead catfish, Ictalurus nebulosus. J. Comp. Neurol. 217:1-16.

TOYODA, J., AND K. UEMATSU. 1994. Brain morphogenesis of the Red Sea bream, Pagrus major (Teleostei). Brain Behav. Evol. 44:324-337.

TrIQUES, M. 1993. Filogenia dos generos de Gymnotiformes (Actinopterygii, Ostariophysi), com base em characters esqueleti$\cos$. Communicaciones do Museu Ciencias PURCS, ser. zoologia, Porto Alegre 6:85-130.

Tuge, H., K. UChiHashi, AND H. Shimamura. 1968. An atlas of the brains of fishes of Japan. Tsukiji Shokan Publ. Co., Ltd., Tokyo.

UCHIHASHI, K. 1982. On the morphological development of the Lobi Inferiores of bony fishes which came into being in the different ages. Mem Fac. Agri. Kinki Univ. 15:55-66.

VIETE, S. 1991. Development of multiple maps of the electrosensory lateral line lobe (ELL) in Eigenmannia. Soc. Neurosci. 17; 1405.

Vischer, H. A., M. J. Lannoo, and W. H. Heiligenberg. 1990. Development of the electrosensory nervous system in Eigenmannia (Gymnotiformes). I. The peripheral nervous system. J. Comp. Neurol. 290:16-40.

VON BAER, K. E. 1828. Uber Enwicklungsgeschichte der Thier. Beobachtung und Reflexion. 3 vols. Borntrager, Konigsberg, Germany.

WAKE, D. B. 1991. Homoplasy: the result of natural selection, or evidence of design limitations? Am. Nat. 138:543-567.

Webster, D. B. 1984. Perspectives on the evolution of neural systems. Am. Soc. Zool. 24:831-833.

West-Eberhard, M. J. 1989. Phenotypic plasticity and the origins of diversity. Annu. Rev. Ecol. Syst. 20:249-78.

WILCZYNSKI, W. 1984. Central neural systems subserving a homoplasous periphery. Am. Soc. Zool. 24:755-763.

WoNG, C. J. H. 1997. Connections of the basal forebrain of the weakly electric fish, Eigenmannia virescens. J. Comp. Neurol. 389:49-64.

Yoshimoto, M., J. S. Albert, N. Sawai, N. Yamamoto, and H. ITO. 1997. Homology of the telencephalic subdivisions in a percomorph teleost with other vertebrates. P. 287 in XIVth international symposium on morphological sciences. International Academic Publishers, Beijing.

Yoshimoto, M., J. S. Albert, N. Sawai, M. Shimizu, N. YamaMOTO, AND H. ITO. 1998. Telencephalic ascending gustatory system in a cichlid fish, Oreochromis (Tilapia) niloticus. J. Comp. Neurol. 392:209-226.

ZAKON, H. H. 1986. The electroreceptive periphery. Pp. 103-156 in T. H. Bullock and W. Heiligenberg, eds. Electroreception. Wiley-Interscience, New York.

ZAKON, H. H., P. WEISLEDER, AND Y. LU. 1995. Electroreceptor afferent terminal morphology is controlled by sensory receptor cell type. P. 185 in Society for Neuroscience Abstracts.

ZupanC, G. K. H., AND I. HorschKe. 1995. Proliferation zones in the brain of adult gymnotiform fish: a quantitative mapping study. J. Comp. Neurol. 353:213-233.

Corresponding Editor: J. Collins

APPENDIX

List of materials examined. Symbolic codes for institutional collections follow Leviton et al. (1985). Data are arranged alphabetically by family, genus, species. Museum acronym and number is followed in parentheses by number of specimens examined, then numbers of specimens perfused and brains sectioned.

Apteronotidae. Adontosternarchus balaenops, UMMZ uncat. JGL-93 (1) 0-0. Adontosternarchus devenanzii, FMNH 100741 (1) 0-1; UMMZ 228972 (1) 1-1. Adontosternarchus sachsi, FMNH 100742 (1) 0-0; UMMZ 228979 (1) 1-1. Apteronotus albifrons; UMMZ uncat. JSA 94-1 (6) 6-6. "Apteronotus" apurensis, FMNH 085499 (1) 0-1. Apteronotus leptorhynchus, UMMZ uncat. JSA 941 (10) 0-1; UMMZ uncat. JSA 94-1 (6) 2-2. Apteronotus sp. A; UMMZ uncat. JGL-94 (1) 0-0. Porotergus compsus, UMMZ 211308 (1) 0-1; UMMZ 228981 (2) 1-0; UMMZ 228982 (2) 0-0. "Porotergus" sp. 1, UMMZ uncat. JGL-94 (2) 0-0. Platyurosternarchus macrostomus, FMNH 100730 (2) 0-2. Sternarchella sima, UMMZ 228975 (1) 0-0; UMMZ 228976 (1) 1-0. Sternarchella orthos, FMNH 100746 (3) 0-3; UMMZ 228977 (1) 1-0; UMMZ 228978 (1) 1-0. Sternarchogiton sp. B, UMMZ 211315 (3) 0-1. Sternarchogiton nattereri, UMMZ 211330 (1) 0-1; UMMZ uncat. JSA 943 (2) 0-0. Stemarchorhamphus muelleri, UMMZ uncat. JGL-94 (1) 0-0; UMMZ 228973 (1) 0-1; USNM 228807 (3) 0-1. Orthosternarchus tamandua, UMMZ uncat. JGL-94 (1) 0-0. Sternarchorhynchus curvirostris, FMNH 100722 (1) 0-1; UMMZ uncat. JGL-94 (1) 0. Sternarchorhynchus oxyrhynchus, UMMZ 228974 (1) 1-1.

Gymnotidae. Electrophorus electricus, UMMZ uncat. CC-92 (1) 1-1 1992. Gymnotus carapo, UMMZ 230734 (2) 0-0; UMMZ 228998 (2) 0-1; UMMZ 228999 (1) 0-0. Gymnotus inaequilibeatus, UMMZ 207025 (2) 0-2.

Hypopomidae. Brachyhypopomus pinnicaudatus, UMMZ 224602 (1) 0-0; UMMZ uncat. JSA 94-2 (1) 0-0; UMMZ uncat. JSA 94-2 (1) 0-0; UMMZ uncat. JSA 94-2 (3) 0-1. Hypopygus lepturus, UMMZ uncat. JSA 94-2 (2) 0-0; UMMZ uncat. JSA 94-2 (2) 0-1. Microsternarchus bilineatus, UMMZ uncat. JSA 94-2 (2) 0-0. Steatogenys duidae, UMMZ uncat. JSA 94-2 (1) 0-1; UMMZ 228994 (3) 1-0. Steatogenys elegans, UMMZ 228996 (3) 0-1.

Rhamphichthyidae. Gymnorhamphichthys hypostomus, FMNH 100744 (1) 0-1. Gymnorhamphichthys rondoni, UMMZ 228997 (10) 0-3. Rhamphichthys rostratus, UMMZ uncat. JSA 94-3 (2) 0-2.

Sternopygidae. Distocyclus conirostris, UMMZ uncat. JSA 94-3 (1) 0-0. Eigenmannia macrops, UMMZ uncat. JSA 94-4 (4) 0-0. Eigenmannia virescens, UMMZ uncat. JSA 94-4 (3) 0-1; UMMZ uncat. JSA 94-4 (10) 0-1. Rhabdolichops caviceps, UMMZ uncat. JSA 94-4 (1) 0-0. Rhabdolichops eastwardi, FMNH 100748 (10) 01; UMMZ uncat. JSA 94-4 (2) 0-1. Sternopygus macrurus, UMMZ 204744 (3) 0-1; UMMZ uncat. JSA 94-5 (2) 0-1. 